\title{
LA SOCIOLOGÍA DE LA FAMILIA EN ESPAÑA, 1978/1998*
}

\section{Gerardo Meil Landwerlin}

Universidad Autónoma de Madrid

\begin{abstract}
RESUMEN
En el presente artículo se analiza la evolución de la Sociología de la Familia en España durante los últimos veinte años, enmarcada en el contexto del desarrollo seguido por esta disciplina en otros países de nuestro entorno cultural-científico y atendiendo tanto a las características temáticas y metodológicas como a su desarrollo en el marco de las instituciones universitarias e institutos de investigación. Así, se revisan las principales fuentes de datos señalando sus virtudes y sus limitaciones desde el punto de vista de esta Sociología particular, al tiempo que se proponen mejoras en el tipo de datos obtenidos. Por otro lado, en el análisis temático se aborda cuáles son las principales cuestiones que guían la investigación y los aspectos de la vida familiar que son investigados, subrayándose las contribuciones que se han realizado, las carencias y posibles líneas de investigación futuras. En conjunto, se puede decir que la Sociología de la Familia en España ha avanzado apreciablemente en los últimos años, aunque todavía queda mucho camino por recorrer.
\end{abstract}

\section{INTRODUCCIÓN}

En 1993, Iglesias de Ussel y Flaquer concluían su revisión sobre el análisis social de la familia afirmando que «la sociología de la familia en España es la

* Nota del editor: Con esta colaboración iniciamos una serie de trabajos que irán exponiendo el "estado de la cuestión" de distintas áreas de la sociología y la ciencia política, y que aparecerán en esta sección de la REIS. 
crónica de una promesa incumplida», pues "a pesar de los considerables esfuerzos desplegados y de los innegables avances realizados en los últimos decenios, cabe reconocer que las inversiones y los empeños investigadores no han rendido todavía todos sus frutos, si bien el nivel de muchos de los estudios pueda ser considerado muy digno" (1993: 69). Un lustro más tarde, no puede afirmarse tampoco que la sociología de la familia española haya alcanzado los niveles logrados en otros países de nuestro entorno cultural, y en cuyas fuentes es obligado beber (Estados Unidos, Francia, Gran Bretaña o Alemania), pero sí cabe constatar que, lejos de eclipsarse el interés por la familia, los estudios dedicados a su análisis científico han continuado creciendo y profundizando en el conocimiento del importante cambio que está registrándose en la actualidad. Al respecto, también hay que señalar que las bases de datos disponibles han mejorado sustancialmente, en parte gracias a la lenta pero cierta integración en el entramado investigador internacional, y singularmente europeocomunitario. En conjunto, no obstante, es preciso reconocer que la producción de estudios de calidad científica contrastada se encuentra muy por debajo de la demanda que, sobre todo desde los medios de comunicación, se hace sobre los aspectos más novedosos del cambio familiar (malos tratos, segundas nupcias, parejas sin hijos, parejas del mismo sexo, organización familiar de las familias de doble ingreso, etc.).

En lo que sigue haremos un análisis de la situación de la sociología de la familia española atendiendo tanto al desarrollo de su institucionalización en centros universitarios e institutos de investigación como a las características temáticas y metodológicas de los estudios publicados en los años a los que se refiere esta revisión ${ }^{1}$.

\section{ORGANIZACIÓN DE LA DOCENCIA Y DE LA INVESTIGACIÓN EN UNIVERSIDADES E INSTITUTOS DE INVESTIGACIÓN}

La sociología de la familia adquiere carta de naturaleza institucional cuando se establece por primera vez la asignatura con dicho nombre en el currículum académico de la Facultad de Ciencias Políticas y Sociología de la Universidad Complutense de Madrid. La proliferación de titulaciones en sociología en los últimos años ha supuesto la normalización académica de la disciplina, que se ha producido con tanto retraso como la propia extensión de la sociología como formación profesional de carácter universitario. Por otro lado, la legisla-

1 Esta revisión es deudora de las revisiones previamente realizadas por M. GARCía FERRANDO, «La investigación sociológica sobre la familia en España, 1959-1984», en M. BELTRÁN et al. (1987), Estudio sobre la familia española, Ministerio de Trabajo y Seguridad Social, Estudios, Madrid, pp. 297-365, y J. IgLesias De UsSel y Ll. Flaquer (1993), «La Sociología de la Familia en España: un intento de interpretación», Revista Española de Investigaciones Sociológicas, 61, y reimpreso en J. IGLESIAS DE USSEL (1988), La familia y el cambio político en España, Tecnos, Madrid, pp. 319-354. 
ción sobre el Doctorado que se introduce en 1985, y en virtud de la cual se establece la obligación de elaborar Programas de Doctorado que tienden a tener cierto grado de orientación específica en la formación de los doctorandos, ha contribuido también al desarrollo de los estudios sobre la familia, incluso en aquellas universidades que no disponían de licenciatura en sociología.

Fuera del ámbito de las universidades han sido varias las instituciones que han abordado la investigación y/o la producción de datos sociológicamente relevantes para el estudio de la familia. Entre estas instituciones destaca en primer término, como es obvio, el Instituto Nacional de Estadística, encargado de la realización periódica de los censos y padrones de la población española, así como de producir datos periódicos sobre la evolución de las principales variables demográficas y familiares (nupcialidad, natalidad y mortalidad, relación con la actividad económica, entre otras). La relevancia de esta información para el estudio de la familia ha sido tradicionalmente de un alcance muy limitado. Solamente a partir del censo de 1970, en el que se comienzan a utilizar las categorías de clasificación de los hogares familiares según la tipología elaborada por P. Laslett, se logra un avance realmente importante al permitir iniciar el análisis de la morfología familiar, uno de los temas de investigación que más atención ha concitado en las dos últimas décadas (De Pablo et al., 1975; Flaquer y Soler, 1990; Flaquer, 1990; Solsona y Treviño, 1990; Requena y Díez de Revenga, 19936, 1995; J. Iglesias de Ussel [dir.], 1994; I. Alberdi [dir.], 1995). El grado de desagregación en la presentación de los datos y la inclusión de criterios relevantes desde el punto de vista de la sociología de la familia han aumentado sustancialmente de un censo a otro, y de forma particularmente importante en el censo de 1991, que, además, ha sido objeto de una explotación más pormenorizada en determinadas Comunidades Autónomas (Madrid, Cataluña, País Vasco). Las características de esta explotación no han permitido dilucidar, sin embargo, algunas de las cuestiones más intrigantes sobre el cambio familiar en España, como, por ejemplo, en qué medida las familias nucleares ampliadas representan una vuelta a la familia tradicional a través de la incorporación a la familia nuclear de los padres que se han quedado solos y ya no pueden valerse por sí mismos.

Para el estudio del cambio del rol familiar de la mujer/madre es de interés, sobre todo, la Encuesta de Población Activa, cuyos criterios de publicación, sin embargo, no presentan prácticamente sensibilidad alguna a esta dimensión, al limitarse a considerar como variables familiares independientes solamente el sexo y el estado civil, lo que imposibilita un análisis de las pautas de actividad y características laborales de las mujeres en función del número de cargas familiares en el hogar o la edad de los hijos (y, por tanto, la fase del ciclo familiar en que se encuentran). Y ello a pesar de que se recogen datos sobre el número de miembros que componen el hogar, su relación con la persona principal y si son mayores o no de 16 años. No obstante, sobre la base de los microdatos de estas encuestas se han realizado algunos estudios relevantes para el análisis de este aspecto del cambio familiar (Requena y Díez de Revenga, 1993b, 1995; 
Garrido, 1993; Meil, 1998), que tienen que ser complementados con los informes anuales sobre el empleo de Eurostat (singularmente el correspondiente a 1993, en el que se encuentra un capítulo específico dedicado al trabajo extradoméstico de la mujer) basados en su propia encuesta sobre la población activa.

Un avance muy importante para la sociología de la familia supuso la realización en 1991 de la encuesta sociodemográfica sobre la base de una muestra de 62.000 hogares, y ello a pesar de las dudas que sobre su adecuada representatividad existen, pues en ella se aborda un muy rico material sobre las relaciones entre los miembros de la unidad familiar y sus biografías familiares, educativas y laborales. De especial interés resulta, sobre todo, el tomo II, volumen I, «Hogar y Familia», donde se recogen datos sobre la estructura de los hogares según la relación que existe entre sus miembros; a partir del sujeto de referencia se proporcionan datos sobre aspectos de la biografía de la relación con sus padres, con sus hermanos y con sus hijos, y, por último, se recogen valiosos datos sobre matrimonios y uniones de hecho. En esta fuente es, por ejemplo, donde cabe encontrar mayor información sobre las biografías de pareja de la población española, lo que permite comprobar no sólo el alcance de las uniones de hecho, sino cómo es utilizada esta forma de convivencia en la biografía familiar de las personas. De igual forma, y también a título de ejemplo, puede encontrarse valiosa información sobre las características y situación familiar tras la ruptura y la articulación de uniones sucesivas. Como aspectos críticos habría que señalar algunas importantes lagunas en los planes de tabulación para dilucidar aspectos relevantes sobre el cambio familiar (biografías laborales de las mujeres casadas en función de la fase del ciclo familiar, homogamia de clase y edad de los cónyuges, entre otros), pues, en general, los datos están presentados tomando como referencia los individuos más que su posición social dentro de la familia, al haber renunciado explícitamente en su diseño a recoger la figura del cabeza de familia. La posibilidad de acceder a los microdatos palía, en parte, estas limitaciones, si bien con un coste de tiempo extremadamente elevado dada su gran complejidad, aunque proporciona abundante material para una explotación específica, que hasta el presente no ha sido tan amplia como en principio cabría esperar y, en cualquier caso, sería deseable. Para el análisis de las condiciones económicas de las familias, tal como lo hace, entre otros, M. a Ángeles Durán en sus trabajos sobre la producción doméstica (1987; Alberdi [dir.], 1995), es de interés, sobre todo, la Encuesta de Presupuestos Familiares, ya que permite un acercamiento a la estructura de gastos e ingresos de los hogares.

Entre los últimos avances en la producción de datos sobre la vida familiar se encuentra el Panel de Hogares de la Unión Europea, que posibilita un análisis, por un lado, de la evolución de las estructuras familiares de los hogares (aunque con problemas en la definición de las familias monoparentales), de su equipamiento y su situación económica (fuentes de ingresos y suficiencia). Por otro lado, también permite analizar, entre otros aspectos, la evolución de sus miembros en relación con la actividad, y ello de una forma complementaria a como se hace en la EPA al distinguir entre actividades laborales con más y 
menos de quince horas semanales de dedicación y al incluir expresamente información sobre cuidado de terceras personas (niños y adultos) y su percepción como impedimento para realizar un trabajo remunerado.

Un lugar muy especial entre las instituciones dedicadas a la investigación sobre la familia merece el Centro de Investigaciones Sociológicas, tanto por su labor editorial como por su labor investigadora. Si la primera se refleja sobradamente en el listado bibliográfico que figura al final de este artículo, su labor investigadora se ha materializado en las encuestas periódicamente realizadas por su personal y disponibles para su explotación por los investigadores. Son muchas las encuestas en las que se encuentran datos relevantes para la sociología de la familia, pero existe un número de ellas que por su temática son especialmente relevantes para esta sociología particular. Cronológicamente hay que destacar en primer término el estudio 1087, de mayo de 1976, en el que se abordan distintos aspectos sobre la percepción y actitudes ante el cambio familiar en ese momento (educación sexual, noviazgo, relaciones prematrimoniales, roles femeninos y masculinos, trabajo extradoméstico de la mujer, divorcio), así como sobre la toma de decisiones, las relaciones familiares y las relaciones entre padres e hijos. Algunos de estos aspectos se amplían y completan en el estudio 1147, de enero de 1978, en el que se profundiza monográficamente sobre las actitudes ante el divorcio y la planificación familiar.

El estudio 1234 (junio de 1980) está dedicado a la pareja humana (universo: población mayor de 18 y más años) y en él se recogen datos sobre opiniones y actitudes ante el matrimonio y la cohabitación, sobre los conflictos familiares y el divorcio, sobre el trabajo extradoméstico de la mujer y la educación de los hijos. Además de actitudes y opiniones, se recogen también datos sobre comportamientos en relación a la distribución de tareas, toma de decisiones, grado de comunicación y desavenencias conyugales. Lamentablemente, este importante estudio para el conocimiento de las pautas de interacción familiar, y en el que se abordan conjuntamente múltiples dimensiones de la vida familiar, no ha sido replicado con posterioridad.

El estudio 1433 (octubre de 1984), titulado "Desigualdad familiar y doméstica» y dirigido por M. a Ángeles Durán, aborda a partir de las respuestas dadas por amas de casa de 18 o más años, entre otros aspectos, la ideología de los roles familiares, las pautas de división del trabajo doméstico entre los cónyuges (incluyendo la ayuda de terceras personas), la participación del padre en el cuidado y atención de los hijos, así como las pautas en la toma de decisiones. Este estudio es ampliamente analizado en Durán (1987).

El estudio 1867 (abril de 1990), titulado «La desigualdad social en la vida familiar y doméstica (II)», representa sólo en una limitada medida una réplica del estudio 1433, porque si bien explora las concepciones de los roles familiares, las pautas de toma de decisiones y la división del trabajo doméstico, lo hace mediante unos indicadores que dificultan enormemente la comparación entre unos datos y otros. Además de estos aspectos, en este estudio se abunda también en distintas representaciones sociales sobre el papel y cualidades de 
hombres y mujeres en la política y en el trabajo, de particular interés para la sociología del género.

El estudio 1875 (octubre de 1991) explora específicamente las actitudes y opiniones de los españoles ante la infancia, abordando cuestiones tales como, entre otras, los modelos de relación de las generaciones en cuanto a tareas de atención y cuidado de los menores, determinados aspectos de los estilos de socialización y las opiniones sobre la influencia del trabajo extradoméstico de la madre sobre la socialización de los menores. Además de estos aspectos, también explora la valoración del sistema escolar y de la política familiar del gobierno. Buena parte de estos datos son explorados más a fondo en el estudio 1973 (julio de 1991), sobre ocio y familia, que recoge datos de padres de ambos sexos sobre tiempos dedicados en días laborables y festivos a las principales actividades vitales tanto del entrevistado como del cónyuge (entre ellas, trabajo doméstico, extradoméstico y cuidado de niños), así como la frecuencia con la que se realizan una serie de actividades de ocio y con quién se realizan, además de la satisfacción que producen. De interés para la sociología de la familia son, sobre todo, distintos aspectos abordados sobre las relaciones entre padres e hijos (prácticas de ocio, cuidado y atención, expresiones afectivas y ámbitos de conflicto), recogiendo, además, en determinados aspectos diferencias en función del sexo de los hijos.

El estudio 1965 (mayo de 1991), titulado "Familia y formas de convivencia», tiene por objetivo la identificación de las biografías familiares de la población española mayor de 18 años, abordando no sólo los estatus civiles que se han tenido y su duración, sino también si el vínculo matrimonial fue religioso o civil, las razones para ello y la tenencia de hijos y la convivencia con los mismos. La información recogida en este estudio se solapa en buena medida con la información recogida en la encuesta sociodemográfica del INE.

El estudio 1990 (marzo de 1992), sobre población y familia, explora las opiniones y actitudes de los españoles ante distintos aspectos del cambio familiar tales como la desinstitucionalización de la vida familiar y la paternidad/maternidad, así como los condicionamientos a la hora de optar por la tenencia de hijos y la necesidad y características de una política de protección social a la familia.

El estudio 2113 (septiembre de 1994), titulado «Familia» y realizado en el marco del International Social Survey Programme, recoge datos de particular interés para analizar en profundidad las concepciones del rol de padre y madre, así como, en menor medida, de marido y mujer, prestando especial atención a la deseabilidad del trabajo extradoméstico de la madre en distintas fases del ciclo familiar, así como la propia realización de un trabajo extradoméstico o no durante dichas fases. Por otra parte, esta encuesta recoge también importantes datos para conocer la práctica de la cohabitación previa al matrimonio, así como sobre las relaciones sexuales (frecuencia, número de personas con las que se han mantenido, sexo y relaciones extraconyugales), abordadas con referencia a la transmisión del SIDA.

Además de estos estudios específicamente orientados a la vida familiar, en 
otros estudios dedicados a los jóvenes, la infancia, la tercera edad o el uso del tiempo también se encuentra valiosa información sobre la vida familiar de la población española. Entre estos estudios hay que destacar, en primer término, los estudios sobre uso del tiempo (1338 y 1339, de julio y octubre de 1982; 1709, de noviembre de $1987^{2}$ ), en los que se recogen datos sobre tiempos dedicados a la producción extradoméstica, a la producción doméstica, al cuidado de niños y al ocio, entre otros aspectos, y que, si bien proporcionan información útil, presentan también importantes lagunas para ser analizados en el contexto de otras dimensiones importantes de la vida familiar (fase del ciclo familiar, número de hijos, ideología de rol, conflictividad conyugal, etc.). Por otro lado, también hay que destacar los referidos a la tercera edad (1792, de febrero de 1989; 2072, de noviembre de 1993, y 2117, de octubre de 1994, así como el barómetro de abril de 1997 —estudio 2244-), en los que se exploran de forma más bien tangencial algunos aspectos sobre características de los hogares en que residen, las relaciones familiares y el grado de satisfacción con las mismas, así como las ayudas que reciben y las representaciones sociales sobre la solidaridad familiar. Los estudios referidos a la infancia se centran, además del ya comentado sobre la educación infantil (estudio 1875), en el maltrato infantil en el ámbito familiar (estudios 2191 y 2202).

Desde el punto de vista de la sociología de la familia, estos estudios presentan algunas limitaciones que es preciso destacar. Así, hay que señalar la ausencia de verdaderos estudios replicativos en momentos temporales suficientemente espaciados para poder observar distintas dimensiones del cambio familiar. Por otro lado, también es preciso destacar la ausencia de datos sociodemográficos básicos sobre ambos cónyuges (nivel educativo, relación laboral, nivel profesional, diferencia de ingresos), lo que permitiría aislar los efectos sobre las pautas de interacción familiar de las bases de poder relativas de cada uno de ellos de los efectos derivados de su lugar en el sistema de estratificación, así como identificar los efectos de la heterogamia sobre la dinámica familiar. Dados los distintos problemas y condicionamientos a los que tienen que hacer frente las familias según la fase del ciclo familiar en que se encuentren y del número de hijos que dependen de ellas, sería deseable también que en aquellas encuestas que aborden aspectos de la vida familiar se incluyan las variables familiares necesarias para poder identificar de una forma razonablemente completa el tipo de familias que se van a estudiar (fundamentalmente, número de hijos y edad del mayor y menor de éstos, número de años que llevan conviviendo los cónyuges, además de las anteriormente indicadas).

Dentro de este contexto hay que señalar también la labor realizada por el Centro de Investigación de la Realidad Social (CIRES), que durante muchos años ha realizado encuestas, ampliamente difundidas, que han permitido conocer mucho mejor nuestra realidad social. Relevante para la sociología de la fami-

2 Analizado en R. Ramos (1990), Cronos dividido. Uso del tiempo y desigualdad entre mujeres $y$ hombres en España, Instituto de la Mujer, Madrid. 
lia ha sido, en primer término, la encuesta sobre "Parejas y matrimonios», de octubre de 1990, analizada en profundidad por Alberdi, Flaquer e Iglesias de Ussel (1994), y en la que se abordan distintos aspectos de las características y circunstancias de su formación, de su estabilidad y ruptura, así como otros aspectos sobre su dinámica interna. El estudio "Familia y uso del tiempo", de febrero de 1993, elaborado con la colaboración de Inés Alberdi, aborda la utilización del tiempo a lo largo del día, tanto entre semana como los fines de semana (qué actividades se hacen a lo largo del día, con quién y dónde); las percepciones subjetivas sobre el uso del tiempo, y distintos aspectos sobre la conflictividad y la satisfacción con la vida familiar. El estudio «El uso del tiempo", de enero de 1996, elaborado con la colaboración de M. ${ }^{a}$ Ángeles Durán, profundiza en el mismo tema pero a partir del tiempo dedicado y su percepción subjetiva a las distintas actividades laborales (domésticas y extradomésticas), de mantenimiento, de descanso y de ocio tanto entre semana como durante los sábados y los domingos. Los resultados de estos estudios se encuentran no sólo disponibles en las bases de datos correspondientes, sino que han sido analizados en los informes que periódicamente se han ido publicando por la Fundación del Banco Bilbao-Vizcaya, y más concretamente en los de los años en los que se realizaron las encuestas.

Los informes periódicos del Instituto de la Juventud también han destinado sistemáticamente un apartado a las relaciones familiares de los jóvenes y a sus actitudes frente a la familia, lo que ha permitido, junto con los informes también periódicos sobre la juventud de la Fundación Santa María, así como con las encuestas sobre juventud del CIS y CIRES, un análisis del proceso de lo que en otro lugar hemos denominado "la postmodernización de la cultura familiar» en España (Meil, 1995). Ahora bien, si disponemos de abundante información sobre las opiniones y actitudes de los jóvenes ante la vida familiar, no puede afirmarse lo mismo, sin embargo y como se verá más adelante, de los comportamientos en el ámbito familiar. A ello hay que añadir, además, que el cambio familiar en actitudes y comportamientos familiares de los jóvenes no ha sido analizado en el contexto del propio cambio en las formas de organización de la vida familiar de los padres (modelos de rol, pautas de división del trabajo doméstico, trabajo extradoméstico de la madre, etc.). En este sentido, sería deseable que estas instituciones abordaran la vida familiar de los jóvenes con mayor profundidad, tomando en consideración también el propio proceso de cambio familiar en el conjunto de la población española.

Entre las instituciones que han contribuido a la profundización de nuestro conocimiento sobre la realidad familiar española requiere también una mención especial la Fundación FOESSA, que en sus informes periódicos sobre la realidad social de España ha incluido siempre un capítulo específico dedicado a la familia. El Centro de Estudios Demográficos de la Universidad Autónoma de Barcelona, así como los informes sobre la situación social de España de la Fundación Encuentro y de la Fundación de la Universidad Complutense, han proporcionado igualmente análisis y datos que han contribuido al mejor conocimiento de la heterogénea y polifacética vida familiar. 


\section{SITUACIÓN ACTUAL Y TENDENCIAS DE LA SOCIOLOGÍA DE LA FAMILIA}

Las líneas de investigación que están desarrollándose actualmente en esta sociología especializada pueden agruparse en distintas dimensiones, a saber: morfología familiar, formación de familias, poder y división del trabajo doméstico, relaciones entre generaciones, conflicto y ruptura familiar y relaciones familia-entorno social. A continuación analizaremos cada una de estas dimensiones por separado, adoptando en la medida de lo posible una referencia comparada con las investigaciones que se realizan en otros países de nuestro entorno cultural. Dado el carácter tan multifacético de la vida familiar y, por tanto, también de la investigación, no puede hacerse justicia en esta revisión a todos los trabajos y a todos los matices abordados en este prolijo campo ${ }^{3}$.

\section{MORFOLOGÍA FAMILIAR}

El estudio de la familia desde el punto de vista de su estructura básica como unidad de convivencia es tan antiguo como la propia sociología de la familia, pues ya el análisis de las consecuencias de la industrialización para la familia realizado por Le Play descansaba, precisamente, en su distinción entre la familia patriarcal y la "familia inestable» o nuclear. Durante mucho tiempo, el interés científico en este ámbito estuvo en España centrado, sobre todo, en el estudio de la familia troncal, y fueron los antropólogos los que proporcionaron (y continúan haciéndolo) excelentes estudios locales en este sentido. No será, sin embargo, hasta que Laslett (1972) y el grupo de Historia de la población de Cambridge desafiaran, en los sesenta, la creencia convencional de que la familia conyugal era consecuencia de la industrialización cuando los estudios sobre la morfología familiar pasan a primer plano de interés científico en España, gracias, sobre todo, también a que el INE comienza a recoger, como se ha indicado, datos que permiten un análisis en tal sentido.

La orientación que han tomado en España los estudios sobre la evolución de la estructura familiar puede clasificarse en dos grandes grupos. Por un lado, se encuentran los estudios de carácter histórico, que han tenido como objeto de análisis el alcance, evolución temporal, distribución geográfica, factores determinantes, estructura de relaciones y estrategias familiares (reproductivas, nupciales y de colocación en la estructura social de las nuevas generaciones) de las familias troncales en la zona norte de la Península, así como, en menor medida, de la familia nuclear en el resto de España. Esta línea de investigación

${ }^{3}$ Los estudios en los que se puede observar de forma más completa el estado del conocimiento actual sobre la familia española son el informe sobre la situación de la familia española (Alberdi, 1995) y el capítulo correspondiente a la familia en el informe FOESSA (Iglesias de Ussel, 1994). 
es desarrollada por los antropólogos sociales y los historiadores de la familia y/o de la población (Barrera, 1990; Cachón, 1987; Cachón y Hernández, 1992; Comas d'Argemir et al., 1993; Lisón, 1996, 1970, 1976; Mikelarena, 1992, 1995; Peristany, 1987; Reher, 1988, 1996; Roigé i Ventura, 1995; entre otros). Por otro lado, se encuentra el interés por la evolución reciente de la morfología familiar al hilo del estudio de las consecuencias para la familia del intenso y rápico proceso de modernización que ha conocido la sociedad española en las tres últimas décadas. Esta línea de investigación, que en buena medida se cruza con la anterior, si bien su marco de referencia es el conjunto nacional en lugar de los estudios de carácter local, es desarrollada por demógrafos y sociólogos de la familia (De Pablo et al., 1976; Conde, 1982; Díez Nicolás, 1983; FOESSA, 1983; Flaquer, 1990; Flaquer y Soler, 1990; Requena y Díez de Revenga, 1990; Valero, 1992; Requena y Díez de Revenga, 1993a; Iglesias de Ussel et al., 1994; Cabré, 1995; Requena y Díez de Revenga, 1995; Valero, 1995).

Una de las cuestiones que se ha abordado en esta última línea de investigación ha sido en qué medida el desarrollo de los hogares sin núcleo, unipersonales y monoparentales representa un cambio profundo en la morfología de la familia, de forma que pueda hablarse también en el caso de España de un proceso de desinstitucionalización similar al que están conociendo los países del centro y, sobre todo, del norte de Europa. La respuesta a dicho interrogante es negativa, pero con matices. Los estudios sobre la cohabitación en España, que dieron el salto desde la dimensión cualitativa (Alabart, Cabré y otros, 1988) a la cuantitativa en los noventa (mediante grandes encuestas, el CIS, en Valero, 1992, y la encuesta sociodemográfica del INE; o de menor tamaño, CIRES, en Alberdi, Flaquer e Iglesias de Ussel, 1995), han puesto de relieve su muy limitado alcance, pero la tendencia que parece apuntarse es claramente creciente, dentro de su limitado alcance. Por otro lado, la cohabitación es más utilizada como matrimonio a prueba que como alternativa al matrimonio, al menos en los casos en los que se busca la tenencia de hijos; no constituye así tampoco primordialmente la vía de recomposición de la biografía familiar tras una ruptura anterior (Meil, 1995). El elevado grado de crecimiento de los hogares unipersonales responde fundamentalmente al envejecimiento de la población y, en muy limitada medida, a la creciente importancia de las rupturas familiares, teniendo la emancipación de los jóvenes de la familia de origen un alcance muy bajo (Iglesias et al., 1995; Vallés, 1993; Garrido y Requena, 1996). Los hogares unipersonales de personas mayores corresponden así a una concepción de la familia basada en la separación residencial de los núcleos familiares que no responde a las consecuencias de la postmodernización de la cultura familiar española reciente, sino a pautas profundamente arraigadas en la historia de la familia española (Reher, 1988, 1996), por lo que no ha de sorprender que su distribución geográfica se corresponda con la geografía del envejecimiento. En relación a los hogares monoparentales se constata su crecimiento, pero esta categoría recoge situaciones familiares muy heterogéneas, pues no sólo recoge 
al progenitor con sus hijos pequeños y dependientes, sino que también incluye la intersección entre los procesos de envejecimiento, retraso en la emancipación residencial y crecimiento de la soltería por grupos de edad. En este sentido, la elaboración y difusión de datos sobre este tipo de familias es deficiente y alcanza, incluso, también al Panel de hogares de Eurostat, lo que ha llevado en ocasiones a malinterpretaciones de la tendencia de cambio familiar.

Ahora bien, el hecho de que el proceso de desinstitucionalización de la familia tenga un alcance muy limitado en la actualidad en España y que tampoco se apunten fuertes tendencias en dicho sentido, por más que sí quepa hablar de una tendencia hacia la pluralización de las formas de vida familiar, no significa que el horizonte normativo sobre las formas socialmente apropiadas del discurrir de las biografías familiares haya permanecido inalterado e inmune al profundo cambio que ha conocido la sociedad española en las últimas décadas. En este sentido, Meil $(1995,1998)$ habla de una postmodernización de la cultura familiar en España al haberse generado un campo de libertad relativa a la hora de conformar las biografías familiares individuales, que ha dotado a los individuos de recursos argumentales para sortear el control social de su entorno en relación a sus proyectos familiares. El hecho de que esta postmodernización de la cultura familiar no haya redundado en una desinstitucionalización importante de la entrada en la vida familiar requiere un estudio en profundidad en el que se combinen técnicas cuantitativas con cualitativas (sobre la emancipación juvenil, véanse Vallés, 1993; Garrido y Requena, 1996; Jurado, 1997; Flaquer, 1997).

Por otro lado, a pesar de que los hogares complejos (múltiples — dos o más núcleos en el hogar-y extensos —un núcleo más otras personas-) se encuentran claramente en retroceso, como consecuencia sobre todo de la decadencia del modo de producción doméstico (y singularmente del agrario) en el contexto de la salarización creciente de la población trabajadora, Requena y Díez de Revenga $(19936,1995)$ ha apreciado una tendencia en aumento de las proporciones de dependencia en el domicilio de una de las familias de origen entre los casados más jóvenes. Esta «nueva complejización» de los hogares sería un fenómeno básicamente urbano, derivado de la crisis del empleo juvenil, y constituiría una respuesta transitoria y no deseada a la crisis de la emancipación entre los estratos sociales con menores recursos; por tanto, una manifestación más de las funciones de bienestar social de las familias realizadas en el marco de la solidaridad familiar. En este sentido, el fuerte proceso de nuclearización que está teniendo lugar en la familia española no debe hacer perder de vista que, por otro lado, se está produciendo una creciente pluralización de las formas de vida familiar que, aunque gira alrededor de la centralidad de la familia conyugal, la perspectiva estática del análisis de la estructura no permite identificar. Sería necesario, por tanto, una recuperación de la perspectiva dinámica del ciclo familiar, introducida en su día por Salustiano del Campo (1982), pero que apenas si ha tenido continuación. Las críticas que la teoría del ciclo vital ha recibido, por sacralizar de hecho la familia nuclear indisolu- 
ble, pueden considerarse superadas con las nuevas reformulaciones que ha recibido (Rodgers y White, 1993; Aldous, 1996; Klein y White, 1996) y pueden constituir un referente a partir del cual profundizar en el análisis del cambio familiar.

\section{FORMACIÓN DE FAMILIAS}

Tras un adelanto sistemático de la edad de matrimoniar durante todo el siglo, y singularmente desde los sesenta, en la década de los ochenta se produjo un descenso muy pronunciado y sistemático de la nupcialidad, al tiempo que se eleva de forma continuada la edad media de nupcialidad. Este abrupto cambio de tendencia, junto con los cambios en la morfología familiar antes referidos y el descenso de la fecundidad, ha sido uno de los procesos que más interés ha despertado, siendo discutidos desde las orientaciones más demográficas en el contexto del análisis de la así denominada «segunda transición demográfica» (Van de Kaa, 1988; Cabré, 1995). El contrapunto a este tipo de orientación demográfica lo han constituido los estudios sobre la juventud, que han analizado dicho fenómeno en el contexto de la emancipación juvenil, al pasar ésta por la constitución de un nuevo hogar independiente de los padres (lo que en la cultura española continúa pasando por el matrimonio). Y es precisamente este hecho, la valoración social del matrimonio frente a la cohabitación, la soltería definitiva y los hogares unipersonales, lo que se ha subrayado, interpretando la caída de la nupcialidad como retraso y atribuyendo éste a la prolongación de la escolarización, a la crisis del empleo y a la carestía de la vivienda. El creciente retraso en la celebración del matrimonio sería así una estrategia de acumulación de capital cara a la constitución de un nuevo hogar, en la misma línea que el denominado "modelo europeo de matrimonio» de la época preindustrial, únicamente que en este caso en un nuevo contexto social y familiar que posibilita la permanencia en el hogar gracias a una profunda revolución silenciosa en las relaciones entre las generaciones dentro del hogar y a la así denominada cohabitación de fin de semana. Aunque se han estudiado distintos aspectos de este retraso en la emancipación juvenil, sería necesario abordar de forma monográfica, como afirman Iglesias de Ussel et al. (1994), también este aspecto.

Más allá de las causas de la caída de la nupcialidad, una de las perspectivas analíticas clásicas de la sociología de la familia en este ámbito es el análisis de los determinantes sociales de la elección del cónyuge. El tránsito de la sociedad preindustrial a la sociedad moderna está caracterizado, entre otras cosas, por la sustitución de la antigua alianza entre familias como vía de transmisión del patrimonio y colocación de sus miembros en la estructura social por el amor como fundamento constitutivo del matrimonio, lo que, en principio, abriría las puertas a unas pautas de formación de las familias potencialmente capaces de alterar de forma radical toda la estructura social, constituyéndose así en un 
potente mecanismo de movilidad social ascendente, así como, por otro lado, debilitar profundamente la propia estabilidad de la institución familiar (Rougemont, 1981). La sociología de la familia ha centrado en este sentido su interés, sobre todo, por un lado, en el análisis de la relación entre el amor romántico y el proceso de nuclearización de la familia (Parsons, 1967; Goode, 1964); por otro lado, en el análisis de las tendencias hacia la homogamia y el funcionamiento de los mercados matrimoniales (Girard, 1964; Kerkhoff, 1964; Kellerhals et al., 1982; De Singly, 1987; entre otros muchos), y, por último, los efectos de la heterogamia sobre la estabilidad conyugal (Kellerhals et al., 1982). No obstante, es preciso señalar que si bien hasta la década de los ochenta éste era un tema habitual en el análisis de la familia, al menos en la sociología francesa y norteamericana, ya en los noventa había perdido buena parte de su atractivo, como lo evidencia el hecho de que no aparezca ni en el índice temático del último manual de teorías de la familia publicado en EE.UU. (Boss et al., 1993).

En España, el debate sobre el alcance de la heterogamia lo abrió A. de Miguel en los años sesenta cuando concluyó, sobre la base de un estudio empírico sobre movilidad social, "que, sobre todo si descontamos la homogamia campesina, el cruzar las barreras sociales a la hora de casarse no es tanto la excepción como la regla» (cit. por Iglesias de Ussel, 1987: 44). Este debate, sin embargo, no se orientó (como señala el mismo Iglesias de Ussel) hacia el análisis del grado de homogamia-heterogamia de las familias españolas y su dinámica de cambio, sino hacia el grado de permeabilidad de la estructura social española. De hecho, los estudios y los datos disponibles para analizar esta dimensión del mercado matrimonial son muy limitados y sus conclusiones no avalan estos resultados. Así, Carabaña (1983), cuyos intereses se centran también fundamentalmente en el análisis de la movilidad social, sobre la base de una muestra de padres de escolares en los municipios de Madrid y Guadalajara tomada en 1975/76, llega a la conclusión de que «la movilidad matrimonial de las mujeres no es mayor que la movilidad profesional de los hombres» y que «la movilidad social de las mujeres [no puede] explicarse a través de su educación, sino en pequeña medida» (1983: 80 y 76). Estos datos, por tanto, evidencian una menor permeabilidad social en la elección del cónyuge (alta endogamia) y un elevado grado de homogeneidad social de las familias (homogamia), que otros estudios españoles no han constatado en la misma medida, como tampoco ha sido constatado en la familia francesa (De Singly, 1987). Así, el análisis de la encuesta sobre familias urbanas en que se basan Del Campo y Navarro (1985: 84) pone de relieve que el grado de movilidad matrimonial de las mujeres no es igual en todos los niveles ocupacionales de sus maridos, dándose con mayor frecuencia a medida que se sube por la escala, si bien entre estratos próximos. A los mismos resultados llega también Iglesias de Ussel sobre la base de percepciones subjetivas de pertenencia a clase (1987: 46; 1994: 434), en vez de partir de datos objetivos de ocupación o educación del marido y de los padres de la mujer, estrategia ésta que, dado el cada vez más extendido trabajo extra- 
doméstico de la mujer casada, resulta crecientemente inapropiada. En este sentido, el acento en el análisis se ha desplazado del estatus heredado al estatus adquirido, fundamentalmente a través de la educación (Alberdi, Flaquer e Iglesias de Ussel, 1994), si bien sería necesario profundizar más en qué medida la "dote escolar», como la denomina De Singly (1987), se traduce, como sostiene que se produce en Francia, en una vía de promoción social para las mujeres.

Entre los factores que conforman la selectividad social que desemboca en la homogamia se han señalado la proximidad residencial, las relaciones primarias y la familia de origen, todas ellas fuertemente relacionadas con la clase social (Iglesias de Ussel, 1987: 27 y 34). Siendo "la calle» (incluyendo en la categoría bares y discotecas) el mercado matrimonial por excelencia, queda por analizar en qué medida determinados medios sociales son más propios de una clase social que de otra y en qué medida los estratos sociales más elevados encuentran su mercado en mayor medida en lugares "cerrados", tal como se ha evidenciado en el caso francés (Bozon y Heran, 1988).

Pero, además de las posibilidades de promoción social a través del matrimonio, la sociología de la familia se ha interesado también por la propia evolución de la estrategia homógama en el contexto del proceso de desinstitucionalización y privatización de la vida familiar y, singularmente, por el fenómeno creciente de la hipogamia. Alberdi, Flaquer e Iglesias de Ussel (1994: 56) han evidenciado que entre las generaciones más jóvenes el grado de homogamia educativa de los cónyuges ha descendido, lo que sugieren puede deberse a la tendencia a una permanencia cada vez más prolongada en el sistema educativo de varones y (en mayor medida) de mujeres. Para el caso de la hipogamia, y desarrollando una hipótesis de Bawin-Legros (1988) sobre la opción por la cohabitación como forma de entrada en la vida de pareja de las mujeres con mayores niveles educativos, los autores sugieren que podría tratarse de una estrategia deliberada para ganar cuotas de poder en el seno de las relaciones conyugales. Del análisis de Meil (1998a) sobre los factores determinantes del cambio en las pautas de división del trabajo doméstico (como expresión de las relaciones de poder dentro de la pareja) se deduce que, al menos entre las parejas con hijos, solamente cuando estas diferencias se traducen en mayor igualdad de ingresos se logra una división del trabajo doméstico menos tradicional. En este sentido, es necesario un análisis más en profundidad de este nuevo fenómeno y de sus consecuencias para la dinámica familiar, así como, más en general, de la influencia de la homogamia-heterogamia en las relaciones internas.

\section{PODER Y DIVISIÓN DEL TRABAJO DOMÉSTICO}

El interés de la sociología de la familia por las relaciones de poder en el seno de la familia se desarrolló en los Estados Unidos al hilo del desarrollo de la familia tipo compañerismo, pero fue a raíz de la publicación del libro Husbands and Wifes (Blood y Wolfe, 1960) y su elaboración de la teoría de los 
recursos cuando comenzó a adquirir gran popularidad. El interés por el análisis de las relaciones de poder en el seno de las familias se ha mitigado en buena medida en los últimos tiempos, a la par que ha crecido cada vez más el interés por el estudio de las normas y pautas de división del trabajo doméstico entre los cónyuges. Tras la clarificación conceptual que se produjo en los setenta y en los ochenta (véase la revisión de Shehan y Lee, 1990), en la actualidad se está tendiendo a interpretar las relaciones de poder primordialmente en términos no tanto de poder de decisión en aspectos fundamentales del nivel o estilo de vida de las familias como en la capacidad efectiva para modificar la división del trabajo doméstico, tendiendo a considerar que solamente en este ámbito se identifica realmente el balance de poder de una relación o su dimensión más importante. Por otro lado, el análisis de la participación masculina en las tareas domésticas ha pasado de la discusión de si era la teoría de los recursos o la disponibilidad de tiempo-sobrecarga de la familia lo que explicaba la escasa participación masculina, a analizar en qué medida la fase del ciclo familiar por la que atraviesa la familia es un factor importante a considerar, y particularmente lo que se ha dado en llamar «schock del primer hijo», o su inclusión en el marco de un modelo general de desigualdad social (M. Coleman y R. Blumberg, 1989).

En la sociología de la familia española, el análisis de las relaciones de poder en el seno de la familia no ha sido, curiosamente, un tema que haya concitado excesivo interés. No obstante, Del Campo y Navarro (1985: 145) han puesto de relieve el profundo cambio que se ha producido en la estructura de autoridad de la familia al comparar datos de encuesta de 1966 y 1980, pasándose de una autoridad dividida por ámbitos y de signo matriarcal o patriarcal a una autoridad compartida y democrática, especialmente en las decisiones que atañen a ambos cónyuges y son altamente relevantes para sus miembros (véase también De Pablo, 1976). Meil (1998b) ha evidenciado no sólo que la norma consensual en la toma de decisiones se ha generalizado aún más (si bien continúa habiendo ciertas decisiones más propias de hombres — coche- y otras más propias de la mujer — colegio de los niños—), sino que, introduciendo la distinción entre poder determinativo y poder distributivo (Kellerhals et al., 1982), ha puesto de relieve cómo, a pesar de la democratización del poder distributivo, el poder determinativo (la carrera profesional) de los maridos no está puesto en cuestión, mientras que el de las mujeres está condicionado por su ideología de rol, su cualificación profesional y los ingresos que obtiene de su trabajo. Por otro lado, también ha evidenciado que el poder de decisión no se solapa con el liderazgo dentro de la relación y que en este sentido tiende a haber una mayor variedad de situaciones, de suerte que el liderazgo del hombre está más asociado con la clase social de pertenencia que con los recursos diferenciales que los cónyuges pueden hacer valer dentro y fuera de la relación conyugal.

La evolución de la división del trabajo doméstico, por el contrario, ha sido una de las dimensiones de la dinámica interna de las familias que mayor inte- 
rés ha concitado, entre otras cosas porque es un ámbito privilegiado para analizar el alcance del cambio familiar (Del Campo y Navarro, 1985; Toharia, 1987; Durán, 1988; Iglesias de Ussel et al., 1994; Inner, 1994; Meil, 1997c y 1998a). El estudio de su evolución en el tiempo se ha visto, no obstante, altamente dificultado y limitado por la gran heterogeneidad de criterios de operacionalización que se han utilizado (Iglesias de Ussel et al., 1994; Meil, 1988a), aspecto que hay que subrayar también en relación a la indagación sobre las pautas de participación de los jóvenes en las tareas domésticas (Meil, 1988b). En este sentido, sería necesario no tanto optar por unos criterios únicos de medida como replicar la utilización de los distintos indicadores en sucesivas encuestas en las que, por otro lado, se recogiera suficiente información sobre los recursos diferenciales de cada uno de los cónyuges, así como sobre otros aspectos fundamentales del cambio familiar. Por otro lado, el interés se ha centrado fundamentalmente en la distribución de las tareas domésticas y del cuidado de los niños entre los cónyuges, descuidando la participación de los hijos en las tareas domésticas. Esta participación se ha abordado casi exclusivamente en las encuestas de juventud, pero en estos casos no se ha analizado (ni se dispone de datos para hacerlo) en el contexto del cambio familiar (incorporación de la madre al mercado de trabajo, ideología de rol de cada uno de los miembros, división del trabajo doméstico entre los padres), no pudiéndose abordar en profundidad sus efectos sobre los modelos de socialización de hijos e hijas en los roles familiares. Los datos analizados por Meil (1987a y 1988b) no permiten, sin embargo, ser muy optimistas en cuanto a una socialización en el seno de las familias menos sexista que en el pasado, aspecto éste que resulta necesario investigar en profundidad.

Sobre los factores que se encuentran tras la mayor participación de los hombres en las tareas domésticas, se ha señalado tradicionalmente su mayor participación en las tareas consideradas típicamente femeninas en aquellos hogares donde la mujer trabaja, tienen unos ingresos mayores, residen en áreas metropolitanas y donde la mujer tiene una ideología de rol más igualitaria (Del Campo y Navarro, 1985; Durán, 1988; Caillavet, 1988). Meil (1987c y $1988 a$ ), por su parte, ha evidenciado entre las familias urbanas un aumento de la participación masculina en el último decenio sobre todo en las tareas domésticas, más que en el cuidado de los niños, pudiéndose imputar esta mayor participación a la mejora de las bases de poder de las mujeres en el seno de la relación conyugal, derivada, por un lado, del trabajo extradoméstico y de los ingresos que de ello obtiene y, por otro, del cambio cultural en los modelos de rol (en la medida en que son asumidos por el hombre), y ello en buena medida independientemente de la disponibilidad de tiempo del hombre. Los datos sobre Barcelona que analiza Subirats (1993), sin embargo, no abundan en la misma dirección, al constatar un escaso aumento de la participación masculina en el hogar entre 1985 y 1990 . Basándose estos estudios en datos transversales, sería deseable la realización de un estudio longitudinal sobre cómo van configurándose los roles familiares y domésticos en los primeros momen- 
tos del ciclo familiar y, singularmente, con el tránsito de una fase a otra. De igual forma, sería deseable también una auténtica réplica de encuestas llevadas a cabo al menos hace una década.

\section{RELACIONES ENTRE GENERACIONES}

El estudio desde la sociología de la familia de las relaciones entre las generaciones se ha orientado fundamentalmente al estudio de las relaciones dentro del núcleo familiar, privilegiando sobre todo las relaciones entre cónyuges y entre éstos y los hijos, al tiempo que se han marginado en buena medida las relaciones entre hermanos y las relaciones fuera del núcleo con las familias de origen. El estudio de las relaciones entre padres e hijos se ha orientado fundamentalmente al estudio de los estilos de socialización (Aldous, 1996; Roussel, 1987), particularmente en relación con las clases sociales y sus condiciones de trabajo (Gecas, 1979; Kellerhals et al., 1982), pero también según la norma de cohesión que rige la vida familiar (Kellerhals y Montadon, 1991), centrando la atención en el grado de autoritarismo, el alcance del apoyo expresivo, el grado de permisividad y el modo de comunicación con los hijos. Más recientemente, el interés se ha centrado en lo que se ha dado en llamar la nueva paternidad, investigándose el significado y el cambio en las representaciones simbólicas, en la ideología y en los significados subculturales de la paternidad, así como en el cambio en las pautas de interacción entre los padres (varones) y sus hijos e hijas, tanto en las familias de procreación como en los casos de ruptura familiar y segundas nupcias (Marsiglio, 1995).

En España, el estudio de las relaciones padres-hijos ha gozado de un interés privilegiado en la sociología de la juventud, donde en los múltiples estudios empíricos que se han realizado ya desde los sesenta (Conde, 1985; Zárraga, 1985, 1989; Toharia, 1989; Orizo, 1990; Navarro y Mateo, 1993; Del Valle, 1994; Velarde, 1994) se han abordado sistemáticamente las relaciones entre los jóvenes y sus progenitores, considerando tanto los aspectos comunicativos, líneas de consenso y conflicto como los valores transmitidos. Los estilos de socialización de los más pequeños, por el contrario, han recibido menor atención, si bien en los últimos años se ha avanzado mucho en este sentido al pasar de la identificación de los principales valores transmitidos a los hijos a partir de encuestas de carácter general (De Pablo, 1976; Del Campo y Navarro, 1985; Alberdi, Flaquer e Iglesias de Ussel, 1994) al estudio específico de los estilos de socialización propiamente dichos (Ministerio de Asuntos Sociales, 1995), o la importante innovación de incorporar a los propios niños como informantes de sus relaciones con los padres (Pérez Alonso-Geta, Marín Ibáñez y Vázquez, 1993; Aguinaga y Comas, 1991; también, Ministerio de Asuntos Sociales, 1995).

Por lo que se refiere a la nueva paternidad, ésta se ha entendido básicamente en términos de la ampliación del contenido del rol parental desde el de 
modelo de masculinidad y "ganapán» a una paternidad más implicada en el cuidado, atención y educación de sus hijos (Durán, 1988; Meil, 1997c, 1998; Valiente, 1997). Por lo pronto, las investigaciones se han centrado en la determinación del alcance y contenido de estos nuevos roles, su contextualización en el proceso del cambio familiar y en la determinación de los factores que se encuentran tras la extensión de una paternalidad más responsable, siendo necesarias investigaciones que profundicen en el significado subjetivo de estos nuevos roles y en sus efectos sobre la dinámica familiar.

El interés de la sociología de la familia por las relaciones con la familia extensa se desarrolló a partir de los sesenta, en buena medida como reacción a la tesis parsoniana del "aislamiento estructural» de la familia moderna, con el objetivo de poner de relieve la densidad de contactos e intercambios entre las generaciones $y$, en este sentido, poner de relieve el diferente papel según las clases sociales, pero en cualquier caso importante, a la hora de lograr un empleo, en la constitución de un nuevo hogar, en las fases de crianza de los hijos o en los últimos años de la vida, y ello desde la doble perspectiva del intercambio de servicios y ayudas, de un lado, y de los aspectos relacionales y simbólicos, de otro. Con el envejecimiento creciente de las sociedades desarrolladas y la crisis del Estado de bienestar, es el papel de las relaciones de parentesco en la vejez y la redefinición de las "obligaciones familiares» en el contexto del proceso de cambio familiar el que en los últimos años, y sobre todo desde el ámbito de la sociología de la vejez, mayor interés ha concitado (Finch, 1989; Walker, 1990; Attias-Donfut, 1995).

En España, a pesar del destacado papel atribuido en general a la red de parentesco, no proliferan los estudios sobre las relaciones intergeneracionales (Alberdi, 1995), si bien con el desarrollo de la sociología de la vejez se ha comenzado a analizar el papel de la familia, y singularmente de la mujer, en el cuidado y atención de las personas mayores, así como sobre las pautas de corresidencia en el hogar de los hijos o de visita a los mismos (Durán, 1988; INSERSO, 1989; Rodríguez, 1994; Bazo y Domínguez-Alcón, 1995, 1996). Por otro lado, se dispone de cierta información dispersa sobre la densidad e importancia de las relaciones de parentesco, sobre todo porque en las encuestas del CIRES se ha preguntado sistemáticamente sobre la frecuencia de contactos con familiares, vecinos y amigos (CIRES, 1993; Iglesias de Ussel, 1994) o puntualmente sobre la ayuda de los padres en la emancipación de los hijos, tanto a la hora de facilitar contactos para lograr un trabajo como en la propia constitución del capital mobiliario y/o inmobiliario de los hijos (Alberdi, Flaquer e Iglesias de Ussel, 1994; Iglesias de Ussel, 1994). Estos datos evidencian la elevada frecuencia de contactos y la importancia de la solidaridad familiar, pero se hace necesario un estudio monográfico de las relaciones de parentesco en el contexto del cambio familiar, tomando explícitamente en cuenta las distintas fases del ciclo familiar y los distintos tipos de familias (según su morfología, según la definición de los roles familiares y según el grado de fusionalidad). 
En Estados Unidos, los estudios sobre lo que genéricamente denominan «calidad» de la vida familiar tienen una larga tradición y forman necesariamente parte de cualquier estudio de carácter comprensivo que se realice sobre la familia. Los esfuerzos en este sentido se han centrado, por un lado, en la delimitación conceptual de las distintas dimensiones relevantes a la hora de evaluar la calidad de una relación (felicidad, satisfacción, ajuste conyugal, cohesión, implicación, comunicación, consenso, expresividad), así como en delimitar los factores que contribuyen a relaciones satisfactorias y de ahí a la estabilidad familiar (Spanier, 1976; Lewis y Spanier, 1979; Johnson et al., 1986). Uno de los aspectos que más interés ha suscitado en este sentido ha sido la investigación y comprensión de por qué los distintos indicadores utilizados evidencian una evolución cíclica (en forma de «u») en función de la fase del ciclo familiar por la que se atraviesa (Vaillant y Vaillant, 1993), de forma que las fases asociadas a la crianza de los hijos están caracterizadas por una menor calidad en la vida conyugal.

En España, por el contrario, y como sucede con otros aspectos de la dinámica interna de las familias, el estudio de este aspecto de la vida familiar ha conocido un tratamiento muy desigual. Mientras que la dimensión de la calidad de las relaciones entre jóvenes y sus padres en la familia de origen ha despertado un vivo interés que ha trascendido los estudios sobre la juventud, dada la magnitud y trascendencia social del retraso en la emancipación de los jóvenes, la calidad de las relaciones entre los demás subsistemas que conforman la unidad familiar (relaciones conyugales y entre hermanos, o en otras fases del ciclo familiar) o ha sido abordada con carácter más bien puntual o se ha considerado fundamentalmente bajo el aspecto de los malos tratos y la ruptura familiar (concretamente, la separación y el divorcio).

Por lo que se refiere a las relaciones entre los jóvenes y sus padres, el interés se ha centrado en particular en dilucidar la cuestión de si cabe hablar de conflicto generacional o no, en delimitar cuáles son las líneas de conflicto y consenso que presiden las relaciones y cuáles son las estrategias que se han seguido para acomodarse al creciente retraso en la emancipación del hogar. Aunque Zárraga identificó la existencia de un apreciable grado de conflicto intergeneracional en 1985, esta visión no es compartida por los demás investigadores, que sostienen tesis contrarias. Mientras que Toharia (1989) caracteriza las relaciones como coexistencia pacífica, sobre la base de una comunicación limitada, Iglesias de Ussel (1997), sobre la base de indicadores de grado de acuerdo en distintos ámbitos del sistema normativo, sostiene que no sólo no existen indicios de ruptura intergeneracional (también, Del Valle, 1994), sino que las discrepancias disminuyen con el paso del tiempo. Por otro lado, las discrepancias normativas no tienen por qué traducirse en conflictos intensos e insatisfacción con la vida familiar; de hecho, todas las encuestas de juventud realizadas en España evidencian que los jóvenes se encuentran satisfechos en el hogar de sus 
padres, en buena medida porque éstos han dejado de controlar estrechamente a sus hijos. Esta revolución silenciosa en el seno de las familias, en virtud de la cual los padres habrían renunciado al control del comportamiento de los jóvenes, sería lo que habría permitido a la familia funcionar como primera proveedora de bienestar social durante la crisis del empleo juvenil, sin que ello se haya traducido en conflictos sociales abiertos (dada la ausencia de prestaciones sociales para estos colectivos en el modelo de Estado de bienestar español) ni en una profunda crisis familiar. Al respecto hay que subrayar, sin embargo, que los estudios sobre la juventud sólo presentan cómo se evalúa la realidad desde el punto de vista de los jóvenes, pero no la percepción de los padres. Meil (1998b) ha evidenciado, utilizando distintos indicadores (tanto de evaluación subjetiva como de frecuencia de conflictos con los hijos), que el clima familiar sí se resiente a partir de la entrada en la fase del ciclo familiar en que los hijos son adolescentes, sin que ello signifique, sin embargo, un conflicto generacional.

El grado de satisfacción con la vida conyugal y las líneas de conflicto entre los cónyuges han recibido, por el contrario, menos atención (De Pablo, 1976; Del Campo y Navarro, 1985; Alberdi, 1995; Meil, 1998b). Más allá de la pregunta genérica sobre cuáles se cree que son los factores de éxito y de fracaso de la vida conyugal (Toharia, 1987; Orizo, 1990; Eurobarómetro, 1995), el interés en este ámbito se ha centrado, sobre todo, en cuáles son los ámbitos de la vida de pareja que resultan más satisfactorios y los que mayor grado de desavenencias concitan. Más recientemente, Meil (1998b) ha discutido la "calidad» de las relaciones conyugales en el contexto del cambio familiar, bajo la hipótesis de la "trampa de la postmodernización", en virtud de la cual la gran cesura entre los modelos ideales de roles familiares y la práctica cotidiana constituye un potencial de conflicto latente muy elevado (también, Alberdi, 1995), habiendo constatado, sin embargo, que, aunque el grado de conflictividad se eleva entre los cónyuges protagonistas del cambio familiar, el grado de satisfacción con la vida familiar no se resiente. La identificación de los procesos, tanto psicológicos como sociales, en virtud de los cuales se estabilizan estas disonancias constituye uno de los retos planteados a la investigación social en este ámbito, así como es necesario igualmente un estudio más sistemático sobre las pautas de conflicto y resolución de los mismos en distintos tipos de familias. Por otro lado, los indicadores que en estos estudios se manejan hay que calificarlos como de alcance muy limitado, por excesivamente simplificadores de la realidad. En este sentido, es necesario profundizar en la elaboración de indicadores que recojan más dimensiones de la relación, distinguiendo, por ejemplo, como se hace en la literatura americana, entre adaptación o ajuste conyugal y satisfacción, recogiendo la dimensión de comportamientos, por un lado, y de evaluación subjetiva de los mismos, por otro, y referidos a aspectos tales como cohesión, consenso, expresividad afectiva y satisfacción (Spanier, 1976).

Dentro del conflicto familiar, la dimensión que más interés (y preocupación) ha despertado en los últimos años ha sido el tema de los malos tratos a 
mujeres, niños y, en menor medida, a hombres y a la tercera edad. Las investigaciones que se han realizado al respecto, sin embargo, no han sido realizadas desde la perspectiva sociológica, sino que proceden fundamentalmente de la psicología y la medicina. Por otro lado, la mayor parte de los datos disponibles en España proceden de los servicios sociales de las Comunidades Autónomas, aunque recientemente el CIS ha realizado dos encuestas específicas al respecto (estudios 2191 y 2202). Estos estudios evidencian que, estando presentes en todos los estratos sociales, los principales factores asociados a los malos tratos son desempleo, alcoholismo y drogadicción. No obstante, y como se señala en el reciente informe sobre la situación de la familia en España, "parece necesario, sin embargo, un mayor rigor investigador que profundice en los diversos factores que pueden estar incidiendo sobre la evolución de este tipo de violencia y ello desde una perspectiva sociofamiliar que contemple las articulaciones e interacciones que se producen entre los diferentes órdenes y organizaciones de la vida comunitaria» (Alberdi, 1995: 246). De igual forma, sería preciso analizar también lo que cabría denominar "violencia doméstica de baja intensidad" dentro de la vida familiar, tal como lleva realizándose de forma fructífera en los Estados Unidos por Gelles, Straus y sus colaboradores (Gelles y Straus, 1988; Gelles y Cornell, 1990; Stith y Straus, 1995).

Más atención que la «calidad» de las relaciones internas en el seno de la familia ha recibido en la sociología de la familia española la ruptura familiar, y más concretamente el divorcio, incluso antes de que fuera legalizado en 1981 (Alberdi, 1978, 1981, 1986; Borrajo, 1987, 1990; López Pintor y Toharia, 1989), así como sus consecuencias, las familias monoparentales (Iglesias de Ussel, 1988; Almeda y Flaquer, 1995). No ha sucedido lo mismo, sin embargo, respecto a otras formas de la así denominada desorganización familiar, tales como la viudedad (Alberdi, 1988; Alberdi y Escario, 1990), el abandono, las familias vacías, la ausencia involuntaria o los fallos involuntarios (Iglesias de Ussel et al., 1994), que requerirían mayor número de estudios en profundidad. Los principales enfoques desde los que se ha analizado el divorcio en España han sido, por un lado, su contextualización en el marco del proceso de modernización de la sociedad española y de privatización e individuación creciente de la vida familiar y, por otro lado, el análisis de los rasgos socioeconómicos de los separados/divorciados, así como de los factores que se encuentran tras la ruptura matrimonial. Así, se han identificado como factores promotores del crecimiento de la ruptura familiar la conflictividad endémica en las relaciones conyugales (incluidos los malos tratos), el mayor nivel cultural y de clase, el mayor grado de heterogamia de clase, cohabitación previa al matrimonio, así como el matrimonio temprano, factores todos ellos que, salvo la clase, se han identificado también en estudios fuera de nuestras fronteras como propiciadores del divorcio. Entre los factores inhibidores se encontrarían, sobre todo, la dependencia económica y los hijos. Además de una profundización en los aspectos relacionales y familiares que se encuentran tras el divorcio, teniendo presentes los desarrollos teóricos que en tal sentido existen, sería deseable 
igualmente poder conocer con mayor detalle los procesos de inicio y desarrollo de la quiebra de la vida conyugal y las estrategias de adaptación a la nueva situación. En este sentido, son necesarios estudios en profundidad sobre los procesos de reconstitución de las biografías familiares y los aspectos relacionales que conllevan las nuevas situaciones familiares (familias monoparentales, segundas nupcias), que den un paso más allá de los aspectos normativos, morfológicos o demográficos desde los cuales se analizan estos fenómenos en la actualidad.

\section{LAS RELACIONES FAMILIA-ENTORNO SOCIAL}

Las relaciones de la familia con el entorno social en el que se desenvuelve han sido estudiadas, sobre todo, con los subsistemas sociales política, economía y educación, lo que no significa que la influencia familiar no sea objeto de consideración en otros múltiples aspectos de la vida social (consumo, salud, etcétera).

\section{Familia y politica}

Las relaciones entre el sistema político y la familia son, en principio, tantas como lo son las relaciones entre los individuos que viven en familias y los actores políticos, pero el análisis de la familia como grupo o como forma de organización de la vida tiene lugar típicamente a través de la política familiar. Con el fin de la dictadura del general Franco, el interés de los investigadores de la familia se centró casi exclusivamente en la dimensión legal de la intervención del Estado en la dinámica familiar, concretamente en el cambio en el derecho de familia, dejando de lado otras dimensiones de la política familiar (intervención económica e intervención en el medio social de las familias), que fueron discutidas en el contexto del desarrollo de la política social en general o del desarrollo del Estado de bienestar. A medida que el Estado desarrolló medidas para promover la igualdad entre los géneros, el interés se amplió hacia las características de este tipo de política social. Así, se fue perdiendo de vista la conceptualización de la política familiar como una dimensión específica de la política social, con una legitimación, unos objetivos, unos instrumentos específicamente orientados en tal sentido y unos resultados (outputs y outcomes).

A finales de la década de los ochenta, sin embargo, comienza a perfilarse la percepción de la política familiar como algo más que las prestaciones familiares de la Seguridad Social (Rodríguez Cabrero, 1987) y, en la década siguiente, vuelve a emerger la idea y necesidad de una política familiar. Desde el punto de vista de los demógrafos se reivindica la necesidad de una política familiar en virtud fundamentalmente de la caída de la natalidad (Cabré, 1990; Fernández Cordón, 1993), mientras que desde el punto de vista de la sociología de la familia la investigación se desarrolla, por una parte, en la elaboración de un 
esquema interpretativo de lo que puede conceptualizarse como política familiar. Las perspectivas en este sentido pueden clasificarse entre quienes conciben la política familiar como conjunto articulado de mecanismos que tienen por objeto la facilitación de recursos para que las familias cumplan adecuadamente sus funciones (Meil, 1992), la política familiar como protección de la institución familia y quienes la conciben como una política orientada a la protección de los individuos en posiciones socialmente débiles (mujeres y niños). Por otra parte, se desarrolla un análisis de su evolución en el tiempo en sus distintos aspectos, tratando de comprender los factores que se encuentran tras su «evaporación» (Del Campo, 1990; Iglesias de Ussel et al., 1994, 1998; Meil, 1989, 1994, 1995a, 1995b; Rodríguez Torrente, 1996). Por otro lado, y en el ámbito comparativo, también comienzan a proliferar durante la década de los noventa los estudios comparativos de esta política social concreta (Bradshaw et al., 1993; Hantrais, 1994; Gauthier, 1996; Kamerman y Kahn, 1997; Kaufmann et al., 1997); la consideración del caso español no tiene, sin embargo, cabida más que a medida que se van haciendo públicos los trabajos del Observatorio de la Unión Europea de políticas familiares (Ditch et al., 1996).

El desafío que tiene planteado, desde el punto de vista del autor de estas líneas, la indagación sobre este aspecto de las relaciones Estado-familia es, habiendo alcanzado un grado de desarrollo aceptable sobre el análisis de la dimensión de la compensación pública de cargas familiares (considerablemente enriquecida en su dimensión comparativa por los trabajos del Observatorio de la Unión Europea), profundizar en el conocimiento de cómo en el plano del entorno social inmediato en el que se desenvuelven las familias realmente se están habilitando recursos que facilitan el cumplimiento de las funciones sociales por parte de las familias. Ello supone tanto el análisis de los recursos sociales disponibles en el plano local (Ministerio de Asuntos Sociales, 1992) como ampliar la perspectiva también al mundo del trabajo, y concretamente a la promoción de la conciliación de la vida laboral y la vida familiar por parte de los empleadores ("política familiar de las empresas»). Otro aspecto a investigar en este sentido, y que ha sido pasado en buena medida por alto en la discusión sobre la crisis y transformación del Estado de bienestar, es el análisis de las consecuencias (y posibles alternativas de reforma) del proceso de cambio familiar («segunda transición demográfica») en aquellos países que, como España, tienen un modelo de Estado de bienestar de tipo conservador (según la tipología de Esping-Andersen ${ }^{4}$ ), al estar basados en el sistema contributivo de garantías de rentas, descansando éste en el modelo de familia tradicional industrial y donde la protección social se articula a los demás miembros de la familia a través de la técnica de los derechos derivados.

4 G. Esping-Andersen (1995), Los tres regimenes del Estado de bienestar, Ed. Alfons el Magnànim, Valencia. 


\section{Familia y economía}

Las relaciones entre la familia y la economía han sido objeto de atención, sobre todo, en el marco de la teoría social marxista y, singularmente, dentro de la sociología del género, así como en el marco de otras disciplinas de las ciencias sociales, particularmente dentro de la economía (nueva economía de la familia e intentos de cuantificación de la producción doméstica) y la psicología (consecuencias de la doble jornada de la mujer y de las características específicas de los trabajos en términos de stress y otros trastornos psicológicos, así como sobre la dinámica de las relaciones conyugales). En el campo de la sociología de la familia, las variables económicas están más o menos explícitamente consideradas en todos los aspectos abordados de la vida familiar, dado el carácter infraestructural que le corresponde, pero la articulación explícita de las relaciones entre ambos subsistemas se ha desplazado desde la discusión de la funcionalidad de la "familia tradicional industrial» para las exigencias de la producción industrial (Parsons) a la explicación de la participación de la esposa en el mercado de trabajo y sus efectos sobre la organización y dinámica interna de la familia, en relación al poder de los cónyuges, a la división del trabajo doméstico y a la calidad de las relaciones entre los cónyuges (satisfacción, conflicto y ruptura familiar), aspectos de los que ya hemos dado cuenta más arriba.

Dentro de la teoría social marxista, la discusión se ha centrado en torno al llamado "debate sobre el trabajo doméstico», donde se discutieron fundamentalmente dos aspectos: por un lado, la naturaleza productiva o improductiva del trabajo doméstico y, por otro lado, la consideración del trabajo doméstico como un modo de producción específico o no y sus relaciones con el modo de producción capitalista (una visión de conjunto puede tenerse en Alonso, 1982; Robertson, 1986; Borderías, Carrasco y Alemany, 1994). El análisis de las relaciones entre el trabajo doméstico y el modo de producción capitalista se ha realizado mayormente en términos funcionalistas, considerando que obedecía a la «lógica del capital» a través de la función reproductora que cumple la familia dentro de este esquema, reproductora del trabajador en la vida cotidiana (regeneración física del trabajador) y generacionalmente (a través de la procreación y socialización de las nuevas generaciones en los valores capitalistas), así como en virtud de la capacidad de reducción de los costes de reproducción del trabajador derivados del trabajo no remunerado de la mujer y/o de su condición de ejército de reserva industrial. Más allá del debate sobre la funcionalidad o no de la familia conyugal para el capitalismo (versión marxista) o para la sociedad industrial (versión parsoniana), una de las consecuencias más positivas de este enfoque (así como del desarrollo paralelo de la nueva economía de la familia) ha sido la reivindicación del papel económico de la familia, no sólo como unidad de consumo o como oferente de mano de obra ${ }^{5}$, sino también en cuanto

5 T. PARSOnS y N. Smelser (1956), Economy and Society: A Study in the Integration of Economic and Social Theory, Free Press, Glencoe. 
unidad de producción de bienes y servicios fundamentales para el bienestar individual de los miembros de la unidad familiar y, en este sentido, evidenciando cómo la economía sigue estando parcialmente «incrustada» dentro de la familia ${ }^{6}$.

En el ámbito español, más allá de la incorporación y discusión de estos modelos teóricos y de la crítica a las categorías económicas convencionales (tanto marxistas como de la economía neoclásica) (véase, sobre todo, Durán, 1993), se han desarrollado importantes esfuerzos por cuantificar la producción doméstica en el plano microfamiliar (Durán, 1988; Caillavet, 1989; Carrasco et al., 1991). Estos estudios, sin embargo, no se han limitado a calcular el valor en términos monetarios de lo producido en el espacio doméstico a partir del tiempo dedicado a las tareas domésticas y de cuidado y atención de los niños y según distintos criterios de valoración (coste de oportunidad, coste de reposición y coste de los servicios), sino que este análisis se ha enmarcado en un contexto más amplio. Así, una línea de análisis ha sido su evaluación en términos relativos frente a otras fuentes de bienestar (trabajo asalariado y prestaciones sociales públicas — salario social-) para las distintas clases sociales (Carrasco et al., 1991). Otros análisis han ampliado la perspectiva a la consideración de su variación temporal a lo largo del ciclo de vida, del año y a lo largo de la semana, así como las características de la sustitución de mano de obra doméstica por mano de obra extradoméstica (solidaria o salarial) y/o por servicios comercializados y las condiciones laborales de la producción doméstica (Durán, 1988; Caillavet, 1988).

Otro aspecto de la relación familia-economía que también se ha abordado en este sentido ha sido el profundo cambio que se está registrando en la definición de los roles familiares y, singularmente, en lo que se refiere al trabajo extradoméstico de la mujer no soltera. La participación de la mujer en la producción destinada al mercado (como autoproducción familiar o como asalariada) ha sido abordada, como ya se ha señalado, desde distintas perspectivas. Desde el punto de vista de la sociología de la familia, el interés se ha centrado, por una parte, en el cambio en las concepciones de rol y en sus condicionantes y, por otro lado, en los cambios efectivos en las pautas de comportamiento. Si los cambios en los modelos de rol y sus condicionantes han sido ampliamente documentados en multitud de estudios (Orizo, 1990; Del Campo, 1991; Martínez Quintana, 1994; Iglesias de Ussel [dir.], 1994; Alberdi [ed.], 1995; Cruz, 1995; Meil, 1988b), no puede afirmarse lo mismo sobre los cambios en los comportamientos laborales de las mujeres no solteras (cohabitantes, casadas, separadas, divorciadas y viudas). Así, en la Encuesta de Población Activa, y por extensión en buena parte de los estudios que se basan sobre la misma, solamente se recogen aspectos básicos de la relación con la actividad según el estado civil, no distinguiéndose además en función del número de hijos menores a cargo, y ello a pesar de que en la encuesta original se recogen datos al respecto

${ }^{6}$ K. POlanyi (1996), El sustento del hombre, Mondadori, Madrid. 
y cuando esta variable resulta fundamental como condicionante de la actividad laboral para el mercado (extradoméstica) (Beltrán, 1987; Garrido, 1993; San Segundo, 1993; Meil, 1998). Si, en el marco de la teoría económica, la participación de las mujeres no solteras en el mercado de trabajo se ha explicado a partir de la teoría del capital humano, los enfoques sociológicos han enfatizado, sobre todo, los condicionamientos familiares (ideología de rol, edad de los hijos e ingresos del marido, además de la educación de las mujeres) y sexuales de tales decisiones. En este sentido, sería altamente deseable el que el Instituto Nacional de Estadística facilitara periódicamente una explotación de la EPA que recogiera los aspectos señalados.

Por otro lado, más allá de los condicionamientos de la actividad laboral extradoméstica de la mujer, también se han abordado otros aspectos de la relación familia-mercado de trabajo, tales como los efectos del paro sobre la estructura de ingresos de las familias, las relaciones entre las generaciones (retardo en la emancipación o solidaridad familiar), la nupcialidad, la fecundidad o la estabilidad familiar, aspectos parcialmente abordados en los anteriores epígrafes (López Pintor, 1988; Alberdi [ed.], 1995; Iglesias de Ussel, 1998). Los problemas de conciliación de vida familiar y vida laboral también han sido objeto de atención preferente, poniéndose en este sentido el énfasis en las estrategias y recursos disponibles y utilizados para compatibilizar las exigencias derivadas de ambas esferas sociales y las dificultades y problemas que de ello se derivan, aunque, como se ha tenido ocasión de comprobar en los epígrafes anteriores, son múltiples los aspectos que en esta relación quedan por analizar.

\section{Familia y otros subsistemas sociales}

Las relaciones de la familia con otros subsistemas sociales (educativo, religioso, sanidad, etc.) han sido exploradas mayormente desde las respectivas sociologías particulares, destacando, entre otros aspectos, el importante papel que cumple la familia en la dinámica y funciones que cumplen dichos subsistemas sociales. Desde la sociología de la familia, al menos en España, estas relaciones apenas si han sido exploradas sistemáticamente, habiendo sido consideradas mayormente bien como variable explicativa (religiosidad), bien como condicionante de las relaciones familiares (la salud en relación a la solidaridad familiar o a las pautas de formación de hogares nucleares ampliados), bien como recurso o como fuente de dificultades en el problema de conciliación de la vida laboral y la vida profesional (el sistema educativo), por citar sólo unos ejemplos. 


\section{CONCLUSIONES}

Como puede observarse a partir de todo lo visto en las páginas precedentes, la sociología de la familia en España ha avanzado apreciablemente en los últimos años, aunque todavía quede mucho camino por recorrer. Además de las líneas de investigación futura apuntadas en los distintos aspectos tratados más arriba, es preciso llamar la atención igualmente sobre la necesidad de que los esfuerzos de desarrollo futuros se encaminen también en dirección hacia una mayor explicitación crítica de los conceptos y del marco teórico utilizado, así como hacia una sistematización del conocimiento bajo la forma de un manual de sociología de la familia, tomando como referencia el análisis de las familias españolas, a imagen y semejanza de los múltiples manuales que existen en el ámbito anglosajón y, en menor medida, en el ámbito francófono. En favor de esta demanda hay que argumentar el carácter sintético y sistematizador, propio de lo que Kuhn denomina ciencia normal, que comporta la realización de un manual de las citadas características. Para lograr una imagen global de estas características que hiciera justicia a la variedad de familias existente sería, sin embargo, preciso un mayor número de análisis comparativos de las familias de las distintas Comunidades Autónomas, así como estudios monográficos según la clase social de pertenencia.

\section{BIBLIOGRAFÍA}

\section{OBRAS DE CARÁCTER GENERAL}

Alberdi, I. (dir.) (1995): Informe sobre la situación de la familia en España, Ministerio de Asuntos Sociales, Madrid.

Aldous, J. (1996): Family Careers. Rethinking the Developmental Perspective, Sage, Thousand Oaks.

Anderson, M. (comp.) (1980): Sociología de la familia, Fondo de Cultura Económica, México.

BAWIN-LEgROS, B. (1988): Familles, marriage, divorce: Une sociologie des comportements familiaux contemporains, P. Madruga, Lieja.

Beltrán, M.; García Ferrando, M.; López Pintor, R.; Rodríguez Cabrero, G.; Thiebaut, C., y Toharia, J. J. (1987): Estudio sobre la familia española, Ministerio de Trabajo y Seguridad Social, Estudios, Madrid, pp. 297-365.

BOH, K., et al. (eds.) (1989): Changing Patterns of European Family Life, Routledge, Londres.

Boss, P.; Doherty, W.; LaRossa, R.; Schumm, W., y Steinmetz, S. (eds.) (1993): Sourcebook of Family Theories and Methods. A Contextual Approach, Plenum, New York.

CONDE, R. (comp.) (1982): Familia y cambio social en España, CIS, Madrid.

CHEAL, D. (1991): Family and the State of Theory, Harvester, Wheatsheaf.

De Pablo, A. (1976): «La familia española en cambio», en Fundación FOESSA, Estudios sociológicos sobre la situación social de España 1975, Euroamérica, Madrid.

De Singly, F. (ed.) (1992): La famille, l'état des savoirs, Editions La Découverte, París.

Del Campo, S. (1991): La nueva familia española, Eudema, Madrid.

Del Campo, S., y Navarro, M. (1985): Análisis sociológico de la familia española, Ariel, Barcelona. 
Flaquer, Ll. (1998): El destino de la familia, Ariel, Barcelona.

FUNDACIÓN FOESSA (1983): «La familia española en la transición política», en Informe sociológico sobre el cambio social en España, 1975-1983, vol. II, Euramérica, Madrid.

Gelles, R. (1995): Contemporary Families. A Sociological View, Sage, Thousand Oaks.

Garrido, L., y Gil Calvo, E. (eds.) (1993): Estrategias familiares, Alianza, Madrid.

IgLesias De UsSel, J. (1996): "Frédéric Le Play: mujer y familia en los inicios de la sociología», en M. A. Durán (ed.), Mujeres y hombres en la formación de la teoría sociológica, CIS, Madrid.

- (1998): La familia y el cambio político en España, Tecnos, Madrid (donde se reimprimen casi todos sus artículos citados más abajo).

Iglesias de Ussel, J.; Flaquer, Ll.; Meil, G.; Alemán, C., y Trinidad, A. (1994): «La familia», en Fundación FOESSA, V Informe sociológico sobre la realidad social en España, Madrid.

Klein, D. M., y White, J. M. (1996): Family Theories. An Introduction, Sage, Thousand Oaks.

MARKEFKA, M. (ed.) (1989): Handbuch der Familienforschung, Luchterhand, Frankfurt a.M.

Martín López, E. (1993): Textos de Sociología de la familia: Una relectura de los clásicos, Rialp, Madrid.

Moors, H., y Palomba, R. (eds.) (1995): Population, Family and Welfare: A Comparative Survey of European Attitudes, Clarendon Press, Oxford.

Robertson, F. (1986): The Family: Change or Continuity?, Macmillan, Londres.

SÁnChez Vera, P. (1993): "Consideraciones metodológicas sobre la investigación de la familia en España», en Revista Internacional de Sociología, 6: 103-125.

- (1994): «Anotaciones para el estudio sociológico de la familia en España. Fuentes y consideraciones metodológicas», en Cuadernos de Realidades Sociales, 43/44.

Segalen, M. (1981): Sociologie de la famille, Armand Collin, París.

- (1992): Antropología histórica de la familia, Taurus, Madrid.

Toulatios, Permuter y Straus, M. (eds.) (1990): Family Measurement Techniques, Sage, Thousand Oaks.

\section{MORFOLOGÍA FAMILIAR}

\section{a) De carácter histórico y antropológico}

BArrera GonzÁlez, A. (1990): Casa, herencia y familia en la Cataluña rural: Lógica de la razón doméstica, Alianza, Madrid.

Bestard, J. (1986): Casa y familia: Parentesco y reproducción doméstica en Formentera, Institut d'Estudis Baleàrics, Palma de Mallorca.

- (1991): «La familia: entre la antropología y la historia», en Papers, 36: 79-91.

Casey, J., y Hernández, J. (eds.) (1997): Historia de la familia: Familia, Parentesco y Linaje, Universidad de Murcia, Murcia.

CHACÓn JiméneZ, F. (ed.) (1987): Familia y sociedad en el Mediterráneo occidental. Siglos XV-XIX, Murcia.

Chacón Jiménez, F., y Hernández Franco, J. (eds.) (1992): Poder, familia y consanguinidad en la España del Antiguo Régimen, Anthropos, Barcelona.

Chacón, F., y Ferrer i Alos, Ll. (eds.) (1997): Historia de la familia: Familia, Casa y Trabajo, Universidad de Murcia, Murcia.

COMAS D'ARGEMIR, D. (1984): «La família en el marc de les transformacions socio-econòmiques del Pirineu d'Aragó", en Quaderns de l'Institut Català d'Antropologia, 5: 44-68.

- (1988): "Household, family and social stratification: Inheritance and labor strategies in a Catalan village (nineteenth and twentieth centuries)", en Journal of Family History, 13, 1: 143-163.

- (1991): «Casa y comunidad en el Alto Aragón: ideales culturales y reproducción social», en Revista de Antropología Social, 0: 131-150. 
Comas d’Argemir, D., y Soulet, J. F. (eds.) (1993): La familia als Pirineus, Conselleria d'Educació, Cultura i Joventud de Andorra, Andorra.

Harris, C. C. (1986): Familia y sociedad industrial, Península, Barcelona.

Laslett, P., y Wall, R. (1972): Household and Family in Past Time, Cambridge University Press, Cambridge.

- (1987): El mundo que hemos perdido, explorado de nuevo, Alianza, Madrid.

LISÓN, C. (1966): Belmonte de los Caballeros: A Sociological Study of a Spanish Town, Clarendon Press, Oxford.

- (1971): Antropología cultural de Galicia, Siglo XXI, Madrid.

- (1976): «Estructura antropológica de la familia en España», en J. Rof Carballo et al. (eds.), La familia, diálogo recuperable, Karpos, Madrid.

López Cordón, M. V., y Carbonell, M. (eds.) (1997): Historia de la familia: Historia de la Mujer e Historia del Matrimonio, Universidad de Murcia, Murcia.

Mikelarena, F. (1992): "Las estructuras familiares en la España tradicional: geografía y análisis a partir del Censo de 1860", en Boletín de la Asociación de Demografía Histórica, 10, 3 : $15-62$.

- (1995): Demografía y familia en la Navarra tradicional, Institución Príncipe de Viana, Pamplona.

Peristany, J. C. (ed.) (1987): Dote y matrimonio en los paises mediterráneos, CIS, Madrid.

ReHer, D. S. (1988): Familia, población y sociedad en la provincia de Cuenca, 1700-1970, CIS, Madrid.

- (1996): La familia en España. Pasado y presente, Alianza Ed., Madrid.

Rodríguez, A., y Peñafiel, A. (eds.) (1997): Historia de la familia: Familia y Mentalidades, Universidad de Murcia, Murcia.

Roigé i Ventura, X. (1995): «Formas residenciales y ciclo familiar en el Priorat (1792-1986). ¿Estructuras o estrategias domésticas?», en Revista Internacional de Sociología, Tercera Época, 11: 139-170.

Rowland, R., y Moll, I. (eds.) (1997): Historia de la familia: Demografia e Historia de la Familia, Universidad de Murcia, Murcia.

\section{b) De carácter sociológico y demográfico}

Alabart, A.; Cabré, A., et al. (eds.) (1988): La cohabitación en España: Un estudio en Madrid y Barcelona, CIS, Madrid.

Alberdi, I. (1993): «La familia, propiedad y aspectos jurídicos», en Garrido y Gil (eds.), Estrategias familiares, Alianza Ed., Madrid.

CABré, A. (dir.) (1995): "Aspectos demográficos de la familia», en I. Alberdi (ed.), Informe sobre la situación de la familia en España, Ministerio de Asuntos Sociales, Madrid.

CONDE, R. (1983): "Tendencias de cambio en la estructura familiar», en Revista Española de Investigaciones Sociológicas, 21.

Del Campo, S. (1982): La evolución de la familia española en el siglo XX, Alianza Ed., Madrid.

Delgado, M. (1994): «La formación de la familia en España», en Revista Española de Investigaciones Sociológicas, 62.

Díez NicolÁs, J. (1983): «La familia en Europa y el cambio social», en Revista Española de Investigaciones Sociológicas, 21: 11-31.

Flaquer, Ll. (1990): «La familia española: cambio y perspectivas», en Salvador Giner (ed.), España: Sociedad y política, Espasa-Calpe, Madrid, pp. 509-549.

- (1991): «¿Hogares sin familia o familias sin hogar?: Un análisis sociológico de las familias de hecho en España», en Papers, 36: 57-78.

- (1997): «La emancipación familiar de los jóvenes», en Revista de Estudios de Juventud, 39: 37-45. 
Flaquer, Ll., y Soler Serratosa, J. (1990): Permanencia y cambio en la familia española, Centro de Investigaciones Sociológicas, Madrid.

Garrido, L., y Requena, M. (1996): La emancipación de los jóvenes en España, Instituto de la Juventud, Madrid.

Jurado, T. (1997): «Un análisis regional de los modelos de convivencia de los jóvenes españoles", en Revista de Estudios de Juventud, 39: 17-35.

MeIL, G. (1995): "La postmodernización de la familia española», en Documentación Social, 98: 25-37.

Muñoz Pérez, F. (1995): «Las parejas sin hijos en España y Portugal», en Revista Española de Investigaciones Sociológicas, 70: 39-65.

Pujol, R. (ed.) (1997): Dinámica de la población en España. Cambios demográficos en el último cuarto del siglo $X X$, Síntesis, Madrid.

REquena y DíeZ DE REVEnGA, M. (1990): «Hogares y familias en la España de los ochenta: el caso de la comunidad madrileña», en Revista Española de Investigaciones Sociológicas, 51: 53-78.

- (1993a): «Formas de familia en la España contemporánea», en Garrido y Gil (eds.), Estrategias familiares, Alianza Ed., Madrid.

- (1993b): «Desigualdad social y dependencia familiar en España», en 1. er Simposio sobre la igualdad y distribución de la renta y la riqueza. Vol. V: Estructura social y movilidad, Fundación Argentaria, Madrid, pp. 59-86.

- (1995): «Estructuras familiares complejas: La formación de familias múltiples en España», en Revista Internacional de Sociología, Tercera Época, 10: 59-86.

Rodgers, R. H., y White, J. M. (1993): «Family development theory», en P. Boss et al. (eds.), Sourcebook of family theories and methods: A contextual approach, Plenum, Nueva York, pp. 225-254.

Roussel, L. (1989): La famille incertaine, Odile Jacob, París.

- (1992): «La famille en Europe Occidentale: Convergence et divergences», en Population, 1 (traducido en Infancia y Sociedad, 16: 103-120).

Solsona, M., y Treviño, R. (1990): Estructuras familiares en España, Instituto de la Mujer, Madrid.

VAlero Lobo, M. A. (1992): «La prevalencia de la familia nuclear en el sistema familiar español», en Revista Internacional de Sociología, Tercera Época, 3: 183-210.

- (1993): «La muerte de la familia: ¿mito o realidad?», en varios autores, Escritos de Teoría Sociológica. Homenaje a Luis Rodríguez-Zúñiga, Centro de Investigaciones Sociológicas, Madrid.

- (1995): «El sistema familiar español. Recorrido a través del último cuarto de siglo», en Revista Española de Investigaciones Sociológicas, 70: 91-106.

Vallés, M. (1993): "Hogar, Familia y Matrimonio», en A. DE Miguel, La sociedad española, 1992-93, Alianza, Madrid, pp. 149-173.

\section{FORMACIÓN DE FAMILIAS}

AgÜero, Y., y Olano, A. (1982): «La intensa caída de la fecundidad y la nupcialidad en España", en Conde (1982: 31-61).

AguinagA, J. (1983): «Hipótesis causales sobre la fecundidad: el papel preponderante sobre la unidad familiar», en Revista Española de Investigaciones Sociológicas, 21.

Alberdi, I.; Flaquer, Ll., e Iglesias de Ussel, J. (1994): Parejas y Matrimonios. Actitudes, comportamientos y experiencias, Ministerio de Asuntos Sociales, Madrid.

Bozon, M., y HéRAN, F. (1988): «La découverte du conjoint», en Population, n. ${ }^{\circ}$ 6, 1987, y n. ${ }^{\circ} 1,1988$.

CaChinero, B. (1982): «Aspectos demográficos de la sociología de la familia: La edad al matrimonio", en Conde (1982: 63-87). 
Carabaña, J. (1983): «Homogamia y movilidad social», en Revista Española de Investigaciones Sociológicas, 21: 61-81.

De Miguel, Amando (1995): "Familia y movilidad social», en La sociedad española, 1994-95, Alianza, Madrid, pp. 261-343.

De Singly, F. (1987): Fortune et Infortune de la femme mariée, PUF, París.

Del Campo, Salustiano, y Navarro, M. (1985): Análisis sociológico de la familia española, Ariel, Barcelona.

FlAQUER, Ll. (1993): «Homogamia, individualismo y familia: modelos de análisis para la formación de la pareja», en Revista Internacional de Sociología, Tercera Época, 5: 69-85.

Girard, A. (1964): La choix du conjoint en France, PUF, París.

Goode, W. J. (1964): The family, Prentice Hall, Nueva Jersey.

Hicks, W. W., y Martínez Aguado, T. (1987): «Los determinantes de la fecundidad dentro del matrimonio en España», Revista Española de Investigaciones Sociológicas, 39: 195-212.

Iglesias de Ussel, J. (1987): Sociología del noviazgo en España, Caja General de Ahorros y Monte de Piedad de Granada.

- (dir.) (1994): «La familia», en Fundación FOESSA, V Informe sociológico sobre la realidad social en España, Madrid.

KercKHOfF, A. (1964): "Patterns of Homogamy and the Field of Elegibles», en Social Forces, 42: 289-297; reimpreso en M. ANDERSON (1980), Sociología de la familia, Fondo de Cultura Económica, México, pp. 157-172.

Kaufmann, J. C. (1993): Sociologie du couple, PUF, París.

Kellerhals, J.; Perrin, J. F.; Steinauer-Cresson, G.; Voneche, L., y Wirth, G. (1982): Mariages au quotidien, ed. P. M. Favre, Lausanne.

MuÑoz PÉREZ, F. (1995): «Procreación y matrimonio en España (1970-1990)», en Revista Internacional de Sociología, Tercera Época, 11: 199-237.

Murstein, B. (1986): Paths to Marriage, Sage, Beverly Hills.

Parsons, T. (1967): Ensayos de Teoría Sociológica, Paidós, Buenos Aires.

Rougemont, D. (1981): El amor y occidente, Kairos (2..$^{\mathrm{a}}$ ed.), Barcelona.

SARrible, G. (1991): Población y desigualdad social, Centro de Investigaciones Sociológicas, Monografías, Madrid.

- (1995): «Maternidad e infecundidad: Más madres, menos hijos», en Revista Internacional de Sociología, Tercera Época, 11: 115-138.

Valero Lobo, M. A., y Lence Pérez, C. (1995): «Nupcialidad, fecundidad y familia. La paradoja del comportamiento de la nupcialidad y la fecundidad en España», en Revista Internacional de Sociología, Tercera Época, 11:89-114.

VAN DE KAA, D. (1988): «Europe's Second Demographic Transition», en Population Bulletin, 42, 1:2-57.

\section{PODER Y DIVISIÓN DEL TRABAJO DOMÉSTICO}

BloOD, R., y Wolfe, D. (1960): Husbands and Wifes: The dinamics of married living, Free Press, Glencoe.

Coleman, M., y Blumberg, R. (1989): "A theoretical look at the gender balance of power in american couple», en Journal of Family Issues, 10: 225-250.

Durán, M. a Ángeles (1987): De puertas adentro, Instituto de la Mujer, Serie Estudios, Madrid.

INNER (1988): Los hombres españoles, Instituto de la Mujer, Serie Estudios, Madrid.

MeIL, G. (1997a): «El papel de los niños en la redefinición del trabajo doméstico en la nueva familia urbana española», en Revista Internacional de Sociología, 16: 39-56.

- (1997b): «La juventud y la redefinición de las pautas de división del trabajo doméstico», en Revista de Estudios de Juventud, 39: 47-65.

- (1998a): «La redefinición de la división del trabajo doméstico en la nueva familia urbana», en Revista Española de Investigaciones Sociológicas, 80.

- (1998b): La postmodernización de la familia española, Editorial Acento, Madrid. 
Ramos Torre, R. (1990): Cronos Dividido. Uso del tiempo y desigualdad entre hombres y mujeres en España, Instituto de la Mujer, Serie Estudios, Madrid.

Shehan, C., y Lee, G. (1990): «Roles and Power», en Toulatios et al., Handbook of Family Measurement Techniques, Sage, Thousand Oaks.

Subirats, M. (1993): «El trabajo doméstico, nueva frontera para la desigualdad», en Garrido Medina y Gil Calvo (eds.) (1993).

TOHARIA, J. J. (1987): «Familia y demografía: aspectos demográficos de la organización familiar», en M. BELTRÁN et al., Estudio sobre la familia española, Ministerio de Trabajo y Seguridad Social, Madrid.

\section{RELACIONES ENTRE GENERACIONES}

Aguinaga, J., y Comas, D. (1992): Infancia y adolescencia. La mirada de los adultos, Ministerio de Asuntos Sociales, Serie Estudios, Madrid.

Attias-Donfut, C. (ed.) (1995): Les solidarités entre générations. Viellesse, Famille, État, Nathan Ed., París.

Bazo, M. T., y Domínguez-Alcón, C. (1995): Cuidado informal en las personas ancianas: Familia, redes y soporte social, Fundación Caja de Madrid, Madrid.

- (1996): «Los cuidados familiares de salud en las personas ancianas y las políticas sociales», en Revista Española de Investigaciones Sociológicas, 73: 43-56.

Borrás Llop, J. M. (ed.) (1996): Historia de la infancia en la España contemporánea, 18341936, Ministerio de Trabajo y Asuntos Sociales, Fundación Germán Sánchez Ruipérez, Madrid.

Bотт, E. (1990): Familia y red social, Taurus, Madrid.

CIREM (1993): Las relaciones intergeneracionales entre personas mayores y adolescentes, Informe de investigación, Dirección General de Protección Jurídica del Menor (mimeo).

Conde, F. (1985): Las relaciones personales y familiares de los jóvenes, Ministerio de Cultura, Instituto de la Juventud, Madrid.

Del Valle, A. (1994): «Vida cotidiana y relaciones personales», en J. Elzo et al., Jóvenes españoles 1994, Fundación Santa María, Madrid, pp. 89-139.

Díez Nicolás, J., y De Miguel, J. (1981): El control de la natalidad en España, Fontanella, Barcelona.

FINCH, J. (1989): Family Obligations and Social Change, Polity Press, Cambridge.

GeCAS, V. (1979): "The influence of social class on socialization», en W. R. Burr et al. (eds.), Contemporary Theories About the Family, Free Press, Nueva York.

Kellerhals, J., y Montadon, C. (1991): Les stratégies éducatives des familles, Delachaux y Niestlé, Neuchâtel-París.

INSERSO (1989): Estudio de familias que conviven con ancianos, Ministerio de Asuntos Sociales, Madrid.

Marsiglio, W. (ed.) (1995): Fatherhood. Contemporary Theory, Research and Social Policy, Sage, Thousand Oaks.

MeIL, G. (1997c): «La participación masculina en el cuidado de los hijos en la nueva familia urbana española», en Paper, 53: 77-99.

Ministerio De Asuntos Sociales (1994): Relaciones padres-hijos, Madrid (investigación dirigida por F. Alvira).

Montoro Romero, R. (1985): La inserción en la actividad económica: empleo y paro juvenil, Informe de Juventud, Ministerio de Cultura, Madrid.

Morente MejÍAs, F. (1996): «La familia ante la vulnerabilidad de la infancia», en Revista Internacional de Sociología, Tercera Época, 15: 123-141.

Musito, G., y Molpeceres, M. A. (1992): «Estilos de socialización, familismo y valores», en Infancia y Sociedad, 16: 67-101. 
Navarro, M., y Mateo Rivas, M. ${ }^{a}$ J. (1993): Informe sobre la Juventud en España, Instituto de la Mujer, Madrid.

Orizo, F. J. (1990): Los valores de los españoles, Fundación Santa María, Madrid.

PÉREZ-OrTIZ, Lourdes (1998): Las necesidades de las personas mayores. Vejez, economía y sociedad, Ministerio de Trabajo y Asuntos Sociales, Madrid.

Pérez Alonso-Geta, Petra; Marín Ibáñez, R., y Vázquez Gómez, G. (1993): Los valores de los niños españoles, Editorial SM, Colección Informes, Madrid.

Qureshi, H., et al. (1989): The Caring Relationship: Elderly People and their Families, Macmillan, Londres.

Requena y Díez de Revenga, M., y Benedicto, J. (1988): Relaciones interpersonales: Actitudes y valores en la España de los ochenta, Centro de Investigaciones Sociológicas, Estudios y Encuestas, Madrid.

Roussel, L. (1995): «La solidaridad intergeneracional. Ensayo de perspectivas», en Revista Espanola de Investigaciones Sociológicas, 70: 11-24.

Rodríguez, J. (1994): Envejecimiento y familia, Centro de Investigaciones Sociológicas, Colección Monografías, Madrid.

TOHARIA, J. J. (1989): «Los jóvenes españoles ante la familia y el matrimonio», en varios autores, Jóvenes españoles 1989, Fundación SM, Madrid.

VAliENTE, C. (1997): «¿Algo más que "ganadores de pan”?: El papel de los hombres en el ámbito familiar en España (1975-1996)», en Revista Española de Investigaciones Sociológicas, 79: 221-243.

Velarde, O. (1994): «Los valores en torno a la familia y la sexualidad», en M. Martín Serrano (ed.), Historia de los cambios de mentalidades de los jóvenes entre 1960-1990, Ministerio de Asuntos Sociales, Instituto de la Mujer, Madrid.

WALKER, A. (1991): "The relationship between the family and the state in the care of older people», en Canadian Journal on Aging, 10, 2.

ZÁrRaga, J. L. (1985): Informe Juventud en España. La inserción de los jóvenes en la sociedad, Instituto de la Juventud, Madrid.

- (1989): Informe Juventud en España 1988, Instituto de la Juventud, Madrid.

\section{SATISFACCIÓN, CONFLICTO Y RUPTURA EN LA VIDA FAMILIAR}

Alberdi, I. (1978): Historia y sociología del divorcio en España, Centro de Investigaciones Sociológicas, Colección Monografías, Madrid.

- (1981): «Sociología del divorcio», en Revista Española de Investigaciones Sociológicas, 13: 183-193.

- (1986): «Divorcio y sociedad en la España actual», en Sistema, 90: 93-112.

- (1988): «Las mujeres viudas y las familias monoparentales», en J. Iglesias de Ussel (ed.), pp. 99-113.

Alberdi, I., y Escario, P. (1990): La situación de las viudas en España: Aspectos cuantitativos, Ministerio de Asuntos Sociales, Madrid.

AlmedA, E., y Flaquer, Ll. (1995): «Las familias monoparentales en España: un enfoque crítico», en Revista Internacional de Sociología, Tercera Época, 11: 21-46.

Barbagli, M. (1990): Probando e riprovando: Matrimonio, familia e divorzio in Italia e altri paesi occidentali, Il Mulino, Bologna.

Borrajo Iniesta, S. (1987): «Estudio sociológico sobre la ruptura familiar en Madrid capital (1981-1984)», en Revista Española de Investigaciones Sociológicas, 37: 113-137.

- (1990): La ruptura matrimonial en España, Eudema, Madrid.

Eurobarómetro (1993): Les Européens et la famille, Comission des Communautés Européennes, Bruselas, n. 39.

Gelles, R. J., y Straus, M. A. (1988): Intimate Violence, Simon y Schuster, New York. 
Gelles, R. J., y Cornell, C. P. (1990): Intimate Violence in Families, Sage, Thousand Oaks.

IGLESIAS DE UsSEL, J. (ed.) (1988): Las familias monoparentales, Instituto de la Mujer, Madrid.

- (1994): «¿Conflicto generacional o armonía familiar? Los jóvenes en España», en varios autores, El precio de la modernización, Iberoamericana, Madrid, pp. 149-183.

- (1997): "Los valores familiares de los jóvenes», en Revista de Estudios de Juventud, 39: 915.

Johnson, D. R.; White, L. L.; Edwards, J. N., y Booth, A. (1986): «Dimensions of Marital Quality: Toward Methodological and Conceptual Redefinition», en Journal of Family Issues, 7: 31-49.

LEWIS, R., y SPANIER, G. (1979): "Theorizing about the quality and stability of marriage», en W. Burr et al., Contemporary Theories about the Marriage, Free Press, Nueva York.

LÓPEZ PInTOR, R., y TOHARIA, J. J. (1989): Separación y divorcio en España. Un informe sociológico, Ministerio de Trabajo y Seguridad Social, Colección Estudios, Madrid.

MeIL, G. (1998b): La postmodernización de la familia española, Ed. Acento, Madrid.

Paul, J., y Arruabarrena, J. (1990): «La investigación en el ámbito del maltrato infantil», en Infancia y Sociedad, 2.

Requena Santos, F. (1996): "Redes de amistad, felicidad y familia», en Revista Española de Investigaciones Sociológicas, 66: 73-90.

Ruiz Becerril, D. (1997): «Los hijos y la ruptura matrimonial», en Revista de Estudios de Juventud, 39: 67-79.

SARrible, G. (1996): «Segunda pareja y diferencias por género», en Revista Española de Investigaciones Sociológicas, 76: 123-139.

Spanier, G. (1976): "Measuring Dyadic Adjustment: New Scales for Assessing the Quality of Marriage and Similar Dyads", en Journal of Marriage and the Family, 38: 15-28.

Stith, S., y Straus, M. A. (1995): Understanding Partner Violence, National Council on Family Relations, Minneapolis.

Vaillant, C. O., y Vaillant, G. E. (1993): «Is the U-Curve of Marital Satisfaction an Illusion? A 40 Year Study of Marriage», en Journal of Marriage and the Family, 55: 230-239.

\section{RELACIONES FAMILIA-ENTORNO SOCIAL}

\section{a) Relaciones familia-sistema político}

Bradshaw, J., et al. (1993): "A comparative study of child support in finfteen countries», en Journal of European Social Policy, 3 (4): 255-271.

CABrÉ, A. (1990): «¿Es incompatible la protección de la familia con la liberación de la mujer?», en Instituto de la Mujer, Mujer y Demografía, Instituto de la Mujer-Universidad Complutense de Madrid, pp. 9-16.

De Miguel, J. M., y Díaz Nicolás, J. (1985): Políticas de población, Espasa-Calpe, Madrid.

Del Campo, S. (1995): «La política familiar en el franquismo» y "La política familiar en la democracia», en Familias: Sociología y Política, Universidad Complutense, Madrid.

Ditch, J.; Barnes, H., y Bradshaw, J. (eds.) (1996): European Observatory on National Family Policies. A Synthesis of National Family Policies 1996, University of York, York (existen informes anuales de síntesis del Observatorio desde 1994; informes anuales por países desde 1990).

FERnÁNDEZ Cordón, J. A. (1993): «Familia y regulación demográfica», en L. Garrido Medina y E. Gil Calvo (eds.), Estrategias familiares, Alianza, Madrid.

Gauthier, A. H. (1996): The State and the Family. A comparative analysis of family policies in industrialized countries, Oxford University Press, Oxford.

Hantrais, L. (1994): "Comparing Family Policy in Britain, France and Germany», en Journal of Social Policy, 23, 2: 135-160. 
Hantrais, L., y Letablier, M. T. (1996): Families and Family Policies in Europe, Longman, Londres.

Kamerman, S., y Kahn, A. (eds.) (1997): Family Change and Family Policies in Great Britain, Canada, New Zealand and the United States, Clarendon Press.

Kaufmann, F. X.; Kuijsten, A.; Schulze, H. J., y Strohmeier, K. P. (1997): Family Life and Family Policies in Europe, Clarendon Press, Oxford.

Iglesias DE UsSel, J. (1997): «Familia y política social en España, 1982-1996», en Anales de la Real Academia de Ciencias Morales y Políticas, 74: 337-382 (reimpreso en Iglesias de Ussel, 1998).

MeIL, G. (1989): «Seguridad Social y familia», en Revista de la Seguridad Social, 42: 43-56.

- (1991): «La política familiar en el año 2000: dilemas y tendencias de la política familiar alemana», en Revista de Estudios Políticos, 72: 259-278.

- (1992): "Política familiar: significado y contenido», en Revista Internacional de Sociología, Tercera Época, 1: 173-191.

- (1993): «La política familiar en el marco actual de reestructuración de los Estados de Bienestar», en X. Roigé i Ventura (coord.), Perspectivas en el estudio del parentesco y la familia, Actas del IV Congreso de Antropología, Tenerife, pp. 115-126.

- (1994a): «La protección social de la infancia», en Fundación Encuentro, España 1993. Una interpretación de su realidad social, Madrid, pp. 367-392.

— (1994b): «L'évolution de la politique familiale en Espagne: du salaire à la politique contre la pauvreté», en Population, 4-5: 959-998.

- (1995a): "La política familiar española durante el franquismo», en Revista Internacional de Sociología, Tercera Época, 11: 47-87.

- (1995b): «Presente y futuro de la política familiar en España», en Revista Española de Investigaciones Sociológicas, 70: 67-90.

Ministerio de Asuntos Sociales (1992): Análisis de la demanda de servicios para la primera infancia, Ministerio de Asuntos Sociales, Colección Estudios, Madrid.

Pitrou, A. (1994): Les politiques familiales. Approches sociologiques, Syros, París.

Rodríguez Cabrero, G. (1987): "Bienestar social y familia en España», en M. Beltrán et al., Estudio sobre la familia española, Ministerio de Trabajo y Seguridad Social, Estudios, Madrid, pp. 231-295.

Rodríguez Torrente, J. (ed.) (1996): Familia y política, Universidad Pontificia de Comillas, Madrid.

VAliente, C. (1996a): «Olvidando el pasado: La política familiar española, 1975-1996», en Gestión y Análisis de Politicas Públicas, 5-6: 156-161.

- (1996b): «El feminismo institucional en España: El Instituto de la Mujer, 1983-1994», en Revista Internacional de Sociología, 13: 163-204.

Zimmerman, S. L. (1995): Understanding Family Policy. Theories and Applications, Sage, Thousand Oaks.

\section{b) Relaciones familia-economía}

Alonso, L. E. (1982): «Sobre el estatuto teórico del trabajo doméstico en la economía política marxista", en Nuevas perspectivas sobre la mujer, Universidad Autónoma de Madrid, Madrid.

BeltrÁN, M. (1987): «Familia y estructura social», en M. BELTRÁN et al., Estudio sobre la familia española, Ministerio de Trabajo y Seguridad Social, Estudios, Madrid, pp. 67-120.

Branen, J.; Mészáros, G.; Moss, P., y Poland, G. (1995): Employment and Family Life. A review of research in the UK (1980-1994), HMOS, Londres.

Borderías, C.; Carrasco, D., y Alemany, C. (eds.) (1994): Las mujeres y el trabajo, Icaria, Economía Crítica, Barcelona.

Bowen, G. L., y Pittman, J. F. (eds.) (1995): The Work and Family Interface, National Council of Family Relations, Minneapolis. 
Caillavet, F. (1987): «El trabajo gratuito de las mujeres: de la economía familiar a la economía nacional», en M. A. Durán (1987: 379-452).

Carrasco, C. (1991): El trabajo doméstico y la reproducción social, Instituto de la Mujer, Serie Estudios, n. ${ }^{\circ} 28$, Madrid.

Durán, M. A. (1984): «La oikos-nomia. El papel de la familia en la economía española», en Cuadernos Aragoneses de Economía.

- (1987): De puertas adentro, Instituto de la Mujer, Serie Estudios, n. ${ }^{\text {12 }}$, Madrid.

- (1993): «La producción doméstica. De la oikonomía a las cuentas satélites», en Del Campo (ed.), Tendencias sociales en España 1960-1990, Fundación BBV, Bilbao, vol. 3.

FERnÁndez, F. (1987): Actividad laboral de la mujer en relación a la fecundidad, Instituto de la Mujer, Serie Estudios, n. ${ }^{\circ}$ 10, Madrid.

Iglesias De Ussel, J. (1998): "Trabajo y familia en España», en Revista Internacional de Sociología, Tercera Época, 11: 171-198 (reimpreso en Iglesias de Ussel, 1998).

IZquierdo, J.; Del Río, O., y Rodríguez, A. (1988): La desigualdad de las mujeres en el uso del tiempo, Instituto de la Mujer, Serie Estudios, Madrid.

LÓPEZ PinTOR, R. (1987): "La crisis económica y sus efectos sobre la familia», en M. BeLTRÁn et al., Estudio sobre la familia española, Ministerio de Trabajo y Seguridad Social, Estudios, Madrid, pp. 197-230.

MARTÍNEZ QUINTANA, M. V. (1992): Mujer, trabajo y maternidad, Instituto de la Mujer, Serie Estudios, n. ${ }^{\circ}$ 30, Madrid.

Moss, P. (1990): Cuidado de los hijos e igualdad de oportunidades. Red europea de formas de atención a la infancia, Ministerio de Asuntos Sociales, Madrid.

Ramos TORRes, R. (1990): Cronos dividido. Uso del tiempo y desigualdad entre mujeres y hombres en España, Instituto de la Mujer, Serie Estudios, Madrid.

Rubio, F. (1982): «El trabajo doméstico y sus vinculaciones con las relaciones de reproducción. Diez años de un debate», en R. Conde (comp.) (1982: 259-282).

SAn Segundo, M. J. (1993): "Los ingresos de los hogares y la estructura familiar», en varios autores, Simposio sobre la Igualdad y Distribución de la Renta y la Riqueza, Fundación Argentaria, Madrid.

\section{ENCUESTAS Y ESTADÍSTICAS}

Instituto Nacional de Estadística (varios años): Censo de Población, varios volúmenes, Madrid. (Los datos del Censo de 1991 están explotados adicionalmente por las propias Comunidades Autónomas, proporcionando una muy rica información sobre la estructura de los hogares.)

- (varios años): Encuesta de Población Activa, varios volúmenes, Madrid.

- (varios años): Encuesta de Presupuestos Familiares, varios años, Madrid.

- (1993a): Encuesta Sociodemográfica, tomo I: Resultados Generales, Madrid.

- (1993b): Encuesta Sociodemográfica, tomo II: Resultados Nacionales, vol. 1: Hogares y Familias, Madrid.

- (1994): Panorámica Social de España, Madrid.

- (1995): Censo de Población 1991, tomo IV: Resultados Nacionales. Características de la Población que vive en Hogares, Madrid.

- (1997): Panel de Hogares, varios volúmenes por publicar, Madrid (en la actualidad está disponible un disquete y el volumen de metodología).

Centro de Investigaciones sobre la Realidad Social (CIRES) (1990): encuesta «Matrimonios y parejas», octubre.

- (1993): encuesta "Familia y uso del tiempo», febrero.

- (1996): encuesta "El uso del tiempo», enero. 
CIS (Centro de Investigaciones Sociológicas) (1976): Evolución de la familia en España, estudio 1087, mayo.

- (1978): Divorcio y planificación familiar, estudio 1147, enero.

- (1980): Pareja humana, estudio 1234, junio.

- (1982a): La vida cotidiana de los españoles, estudio 1338, octubre.

- (1982b): El tiempo libre de los españoles en el fin de semana, estudio 1339, julio.

- (1983): Representaciones colectivas sobre la mujer y la familia, análisis de las actitudes sociales ante el aborto, estudio 1394 , febrero.

- (1984): La desigualdad social en la vida familiar y doméstica, estudio 1433, octubre (analizado en M. a Ángeles Durán, 1987).

- (1989): Encuesta general de población, estudio 1841, publicada parcialmente en REIS, 51, 1990: 237-277.

- (1990): Educación y problemática infantil, estudio 1875, junio.

- (1991a): Las mujeres españolas: lo privado y lo público, Informe de la encuesta 1867, mayo, redactado por Pepa Cruz Cantero y Rosa Cobo, Centro de Investigaciones Sociológicas, Madrid.

- (1991b): Familia y formas de convivencia, estudio 1965, mayo.

- (1991c): Ocio y familia, estudio 1973, julio.

- (1992): Población y familia, estudio 1990, marzo.

- (1993): Apoyo informal a las personas mayores (1. a fase), estudio 2072, noviembre.

- (1994a): Valores y dinámica intergeneracional, estudio 2105, mayo-junio.

- (1994b): Valores y dinámica intergeneracional (población adulta), estudio 2107, junio.

- (1994c): Familia, estudio 2113, septiembre, correspondiente al International Social Survey Programme, julio.

- (1994d): Apoyo informal a las personas mayores (2. a fase), estudio 2117, octubre.

- (1995a): Educación y maltrato infantil en el ámbito familiar, estudio 2191, septiembre.

- (1995b): Actitudes y opiniones ante el maltrato infantil en el ámbito familiar, estudio 2202, diciembre.

EUROstat (varios años): Enquête sur les forces de travail, serie amarilla 3 C, Bruselas.

- (varios años): Statistiques demographiques, serie amarilla 3 A, Bruselas.

\section{ABSTRACT}

This paper analyzes the evolution of Family Sociology during the last twenty years in Spain, paying attention to the evolution of the field in other countries. The analysis covers both the institutional dimension in universities and research institutes and the metodological and substantive questions. Family data sources are reviewed from the point of view of this specific Sociology, pointing out both advances and shortcomings, and suggesting posible improvements in the type of collected data. Research questions in the field are examined, pointing out the dimensions of family life considered, shortcomings and posible lines for further research. Altogether Family Sociology in Spain has improved considerably in the period, but there is still a hard work to do in order to reach equiparable levels of development of the field in other countries. 